\title{
The GPR investigation of the Shakespeare family graves
}

\section{Erica Carrick Utsi and Kevin Colls}

\begin{abstract}
As part of a multi-disciplinary programme of archaeological investigation, GPR was used to investigate the Shakespeare family graves below the chancel of Holy Trinity Church in Stratford, Warwickshire, England. Although William Shakespeare's place as perhaps one of the most famous individuals who has ever lived has been cemented in the annals of history, much of his life and death is still shrouded in mystery. As a result, a large number of myths and legends have grown up around his burial place. These included the suggestion of an unusually deep burial or the presence of a large family crypt beneath the chancel floor. A series of multi-frequency surveys was carried outto establish the depth and structure of the graves and as much burial information as possible. Close survey (using a strategy developed and successfully applied in Westminster Abbey and other churches) was used in order to optimise the quality of patterning in the data. Within Holy Trinity, this strategy was validated by the detection of a known vault.
\end{abstract}

The use of multiple frequencies was critical in this investigation in order both to detect the graves and also to establish information about the graves. Too low a frequency may result in non-detection because of the relatively low target resolution whereas too high a frequency risks insufficient depth penetration.

From this process a number of myths can now be discounted, including the presence of a large Shakespeare family vault or crypt. Instead, the GPR survey suggests that a simple, shallow, earth-cut burial lies beneath William's tombstone. One story however concerning disturbance of William Shakespeare's grave in order to remove his skull does correspond with the evidence.

\section{KEYWORDS}

GPR, Historic Church, William Shakespeare, Multi-frequency Investigation, Detection of grave, Close Sampling 


\section{GOOD FREND FOR IESUS SAKE FORBEARE, TO DIGG THE DVST ENCLOASED HEARE. BLESTE BE $\mathrm{Y}^{\mathrm{E}}$ MAN $\mathrm{Y}^{\mathrm{T}}$ SPARES THES STONES, AND CVRST BE HE $\mathrm{Y}^{\mathrm{T}}$ MOVES MY BONES ${ }^{1}$.}

\section{Introduction}

These immortal words, certainly one of the most famous epitaphs in history, are inscribed on a small, insignificant looking stone in the floor of the chancel of Holy Trinity Church in Stratford-upon-Avon, Warwickshire, England (Figures 1 and 2). The commonly held view is that beneath this stone lies the burial of William Shakespeare, the epitaph, a warning from the bard of a curse should anyone disturb his bones. However, despite an entry in the parish burial records documenting his interment on the $25^{\text {th }}$ of April 1616, there are a great deal of unanswered questions regarding the presence or absence of his burial, the layout, nature and type of his grave, and the relationship between William's burial and those of his relatives whose tombstones are positioned immediately adjacent to his. Given the importance of the site and the ethical and religious beliefs which must be considered, no previous archaeological investigation had taken place, despite many requests from a host of individual researchers and institutions. Perhaps partly due to this, and the overwhelming interest in Shakespeare on a global level, many myths, legends and stories have arisen spanning many centuries on the subject of the presence of the grave, its contents, and tales of grave robbing and disturbance. In 2010, an ambitious research project was initiated to investigate Shakespeare's grave. Work was directed by the Centre of Archaeology at Staffordshire University and assisted by a team of leading experts in the fields of archival research, laser scanning and 3-D modelling, osteology and facial reconstruction, and Ground Penetrating (or Probing) Radar (GPR). Faculty permission was granted, for the first time, to undertake a series of innovative non-invasive archaeological investigations of the chancel floor at Holy Trinity using state of the art radar technology aimed at answering many of the questions surrounding this important place.

\section{Technical background to the investigation}

GPR has been recognised for some considerable time as a useful tech- nology for investigating the subsurface of historic buildings, including churches (Daniels, 2004). GPR surveys have been carried out both in order to understand the structures buried in the subsurface and also to detect potential problem 
areas such as fractures, voids or cracking (e.g. Barone, Di Matteo, Graziano, Mattei, \& Pettinelli, 2010; Bavusi et al., 2010; Lorenzo, Hernández, \& Cuéllar, 2002). Where churches are concerned, it is not uncommon for whole or partial evidence of graves to be discovered beneath the floor in the course of investigations with other objectives, usually structural in nature (Calia et al., 2012; Gabellone et al., 2013; Leucci, 2002; Novo, Lorenzo, Rial, \& Solla, 2010; Utsi, 2006). GPR survey has also been used in order specifically to map all such graves and to locate known tombs considered to be of historical significance (Utsi, 2006; Utsi, 2012).

\section{The Shakespeare family graves}

William Shakespeare was buried in Holy Trinity Church Stratford- upon-Avon, Warwickshire, England on $25^{\text {th }}$ April, 1616, in the chancel of the church (Figure 1). His burial is recorded in the church register (Bearman, 2013). There is no ledger stone on the floor specifically ded- icated to his memory although the famous stone, inscribed with the aforementioned curse, is popularly associated with his grave. Across the remainder of the chancel there are a series of ledger stones dedicated to Ann Hathaway, William's wife, Thomas Nash, husband to William and Ann's granddaughter, Dr John Hall, William and Ann's son-in-law, and Susanna Shakespeare, their daughter. Two further stones complete the series of ledgers, Francis Watts and his wife Anne (Horsler, Gorick, \& Edmondson, 2010). From North to South, the respective positions of the Shakespeare family accord- ing to the ledger stones on the floor are Ann, William, Thomas, John and Susanna. This does not represent their order of burial which was William (1616), Ann (1623), John (1635), Thomas (1647) and, lastly, Susanna (1649). The right for the Shakespeare family to be buried in the Chancel of Holy Trinity was vested in William himself since he had purchased this. The sequence of burials suggested that there might be a reasonably sized family vault at some location below the floor. Internments within a church cause considerable damage to the floor and usually require the floor to be repaired at regular intervals, if not re-laid in its entirety (Rodwell, 2012). Even without the subsequent family burials it would be extremely unusual for there to have been no structural changes within the church during the course of the four hundred years since Shakespeare's death. It was common practice during the $19^{\text {th }}$ century for church floors to be comprehensively re-laid to cope with the post depositional disturbance and the main floor of Holy Trinity Chancel appeared to date to this period. Memorial wall plaques or inscribed slabs do not, of themselves, normally indicate either the numbers of people interred within the church building, or the burial location. These commemorative tablets indicate simply that certain people were buried within that particular church (Rodwell, 2012). As might be expected for such an important historical figure, a number of tales relating to Shakespeare's burial have been created over the years. Early accounts of the Bard's burial focus upon the curse and the incredible depth of the grave. In a letter dated 1694 by anti- quarian William Hall to Edward Thwaites, the 'bone-house', or charnel house at Holy 
Trinity (now absent) is mentioned as the motivation for the curse on William's stone (in an attempt to ward offany disturbance to his own remains). The letter continues to state that William's remains were laid 'seventeen foot down' $(5.18 \mathrm{~m})$ to act as a further deterrent. Other stories are perhaps equally as farfetched as the great depth, for example to account for the small size of the ledger stone, some have suggested that Shakespeare was buried standing up like his contemporary colleague Ben Jonson (who is the only person to be documented as being buried this way in Westminster Abbey) although GPR investigations of themain Abbey floor suggest that this, too, is probably a myth. There is also a school of thought which suggests that, in spite of the evidence to the contrary, Shakespeare was never buried in Holy Trinity and his remains lie in secret in Westminster Abbey.

There are a number of accounts that suggest some type of distur- bance to Shakespeare's grave may have occurred. One such historic account describes the interment of Margaret Davenport in a vault beneath the chancel floor on the $2^{\text {nd }}$ of July 1796 . Three separate accounts of this event exist which state that in excavating the vault, workers accidentally broke through into the tomb of Shakespeare (Crayon's account published 1819-1820, Drake's account 1818, and the diary of Harness of 1844), although the description of what was seen varies from a skeleton to just an empty void. However, the accu- racy of these accounts has never been confirmed. Although no great reliance was placed on any of the stories when designing the survey plan, it was recognised that if any of them were true, they contained potentially interesting information.

\section{The case for multi-frequency surveys}

Given the historical background, the expected factors to be taken into account when planning this survey were:

- The possibility of deep burials at least for William, if not for the rest of his family;

- An expectation that a large family vault might be the target;

- Uncertainty of location relative to the ledger stones at floor level given the reworking of the floor in the $19^{\text {th }}$ century;

- A possibility that the grave was connected to the Davenport fam- ily vault, further to the West, beneath the lower chancel floor; and

- The possibility of moisture in the subsurface given the church's proximity to the River Avon.

During the development phase of this project, an initial GPR survey using a 250MHz antenna was 
carried out by the University of Birmingham (Baldwin, 2013). This proved unsuccessful in locating the graves or the known location of the Davenport family vault. However, it did provide some reassurance, in the absence of specific soil properties information, that the site was suitable for GPR to be used. Since the antenna previously deployed was a relatively low frequency, it was decided to use a mixture of frequencies for different purposes. Accordingly, a 400MHz antenna was selected to test whether or not it was possible to detect the graves, specifically testing against the known position of the Davenport family vault, and also to test for the possibility of a deep burial. The full depth potential of this (or any other) antenna depends upon the relative mixture below the surface of soil, air gaps and moisture as well as the electromagnetic response of the soil itself. Although it was extremely unlikely that it would have the ability to penetrate to the full theoretical burial depth, especially if moisture were present, this at least allowed an examina- tion of lower deposits and the opportunity to see lower levels of disturbance of the subsurface which might either detect the burial or suggest that the burial extended beyond its depth range.

A $1.5 \mathrm{GHz}$ antenna was selected to examine the near surface in greater detail. Although theoretically a $1 \mathrm{GHz}$ antenna might have been a more obvious choice, previous experience of grave location within Westminster Abbey and other churches coupled with the findings of soil research indicate that the slightly higher frequency is potentially a better choice (Utsi, 2012). The salient point is that although electrical losses vary directly in proportion with frequency, magnetic losses do not. Magnetic losses peak just under $1 \mathrm{GHz}$ and then decrease (Serbin, Or, \& Blumberg, 2001; Thomas, Metje, Rogers, \& Chapman, 2006). The result is that signal attenuation may have a lesser effect on antenna frequencies above $1 \mathrm{GHz}$ than at this frequency although the depth constraints still remain (cfUtsi, 2012). Although the results of the radar survey will depend on the electromagnetic response of the soil and surface stone, this means that either a lower or a slightly higher fre- quency is potentially a more powerful tool.

Following the results of these first two surveys, once it had become apparent that the only visible graves were shallow, a $4 \mathrm{GHz}$ antenna was also used in order to test whether it was possible to improve target detection and definition.

The radar used for the survey was an Utsi Electronics' GroundVue3_1, a single channel, multifrequency radar. All antennas were used on reduced size skids rather than the traditional trolley in order to maximise the number of readings and minimise data lost due to the offset from walls, the upper altar step and church furniture. A single channel radar was preferred to a multi-channel because of the space restrictions.

The chancel floor is divided into three sections. Of these, the western end (lower chancel floor, 
Figure 2) is the largest area, covering the Davenport family tomb in its NE corner. A step divides this area from the central area of the upper chancel floor which con- tains the Shakespeare family ledger stones in a neat North-South line across the church with the Watts' stones directly to the South of this group (Figure 2). Along the western edge of the central area there is a metal grille at floor level and a metal communion rail. Another step divides the central area from that immediately in front of the altar, referred to in this paper as the altar step and marked as lower altar step in Figure 2. This lower altar step has two further steps directly in front of the altar, placed centrally and is also partially obscured by a large monument on the North side (Figure 2). All of the ledger stones are currently placed so that their eastern edges abut the western edge of the lower altar step although the stones themselves lie in the eastern area of the upper chancel floor (cf Figure 2).

The account of the survey which now follows begins with the investigations of the primary area of interest, the upper chancel floor. The upper chancel floor incorporates the ledger stones commemorat- ing the various members of the Shakespeare family and has been the presumed area of their burial (Figure 2). For the first two surveys $(400 \mathrm{MHz}$ and $1.5 \mathrm{GHz})$ the investigations included the eastern end of the lower chancel floor so that the survey strategy could be validated by the detection of the Davenport vault whose position in the NE corner of this area, immediately adjacent to the steps leading to the upper chancel floor, was known. Following the successful outcome of these two surveys, a $4 \mathrm{GHz}$ investigation of the upper chancel floor was carried out to see if target definition could be improved and to test for the presence of small metal artefacts.

Once the results of the surveys of the upper chancel floor were completed, the survey was extended eastwards into the lower altar step with the $400 \mathrm{MHz}$ and $1.5 \mathrm{GHz}$ antennas in order to test whether ornot the graves continued below this step. The $4 \mathrm{GHz}$ was not used in this area due to the height of the step relative to the penetrative range of the antenna.

\section{The first 400MHz survey: upper chancel floor (including ledger stones) and lower chancel floor}

In order to ensure the best target definition achievable with this frequency of antenna, a full area survey was carried out over the area of theledger stones and a sufficient length of the main chancel floor to ensure that the Davenport family tomb had been included in the survey. The probing depth, as measured by the two-way travel time, was set to $100 \mathrm{~ns}$ which is equivalent to $5 \mathrm{~m}$ on the basis of the calibrated velocity of $0.1 \mathrm{~m} / \mathrm{ns}$. Readings were taken every $3 \mathrm{cms}$ along the line of travel of the radar. Since Christian burials are oriented West/East, the data were collected along North/South parallel 
lines at $25 \mathrm{~cm}$ transect spacings. This is half the spacing recommended in theEnglish Heritage guidelines and reflects the relatively small survey area and the aim of maximising data points in order to enhance the definition of the targets, in line with the strategy developed and used in Westminster Abbey (English Heritage, 2008; Utsi, 2012).

Transmission velocity calibration was carried out by curve fitting which confirmed dry conditions and a transmission velocity of $0.1 \mathrm{~m} / \mathrm{ns}$. It is known that the level of the groundwater rises when the nearby river Avon is in flood. This velocity is consistent with the observed level of the river at the time of the survey, approximately $2 \mathrm{~m}$ to $3 \mathrm{~m}$ below the ground surrounding Holy Trinity Church. All 2dimensional data is displayed North to South from left to right and all 3-dimensional data is oriented so that East is at the top of the image. Data processing has been limited to ensuring depth accuracy by elimination of Tzero, an overall background removal to enhance the visibility of anomalous material, the addition of exponential time based gain to compensate for attenuation and the application of a Bandpass Butterworth filter to fit the transmission and reception parameters of the antennas used. After processing the processed and raw data files were compared in order to ensure that the sequence of processes applied had not introduced spurious targets.

It was evident from the first survey line, taken along the eastern edge of the survey area, that there were shallow graves present (Figure 3). The two lines illustrated demonstrate not only the shallow depth of the signal responses but also some ringing from these near surface features which is suggestive of air gaps. In the right hand line there is additional ringing from the brass plaque at floor level on Ann Hathaway's ledger stone (to the left of the plot). Much of the data below c. 30ns is taken up with ringing but careful examination shows that there is at least one stratigraphic change in there as well, in the irregularly shaped line around 40ns. The crossed lines at the foot of the plot, at around $4 \mathrm{~m}$ in depth correspond to air signals from second- ary reflections returned from the Chancel roof.

The survey was continued from the area of the upper chancel floor down across the step at its West end and on to the lower chancel floor. The Davenport family vault is clearly visible in the data from this area, on the left hand side of each radargram (Figure 4). There is evidence of another major feature to the South (right hand) side with considerable ringing below which might indicate the presence of metal in this area. This confirmation of the position of the known vault validated the survey strategy.

Comparison of Figures 3 and 4 make it evident that the graves visible below the ledger stones are both shallower and less substantial than those below the lower Chancel floor. It is also clear that the graves in the area of the ledger stones do not have the same or similar types of structural features as those further 
West and the Davenport tomb in particular. It is not unusual to find different types of grave within a church. The size and contents are a reflection firstly of what currently survives, secondly of the preferred burial practices of the time and sometimes of the social standing and wealth of the individual(s) within the grave. Figure 5 shows comparative data from Westminster Abbey. Many of the extant graves are later in date and a wide variety of substantial grave constructions can be seen but simpler burials similar to those suggested by Figure 3 are also visible, see for example the one centred on $14 \mathrm{~m}$ distance close to the ground surface.

The 2-dimensional data were formed into a 3-dimensional data block without spatial adjustment for the step or the lower floor. In order to diminish the effect of the metalwork along the western edge of the ledger stone area, a lower factor of time based gain was applied before incorporating the data from the affected survey lines. The 3-dimensional data was enveloped before time slices were extracted on the basis of significant changes in data patterning. It was not considered necessary to vertically integrate the time slices since the current floor is not particularly uneven and the changes in patterning with depth were clear.

The time slices confirmed that the horizontal outline of the apparent voids visible in the 2dimensional data corresponded to shapes consistent with graves and that these lay very close to the surface, withinc. $16 \mathrm{~cm}$ (Figure6). The greyscaleused in the time slices indicates strong electromagnetic differences (either positive or negative) in black, minor differences in shades of grey and continuity in white. The roughly rectangular shape of these outlines is typical of the contents of graves where material, either human remains or soil or a mixture, still exists. The black areas are the response from voids which have built up from decomposition although, where a container is used, they may also reflect the space left above the corpse (cf Utsi, 2006). The pale areas indicate the presence of material within the grave. There is a band of irregularly shaped areas of strong signal to the West of these features i.e. between $\mathrm{y}=2.2 \mathrm{~m}$ to $\mathrm{y}=4 \mathrm{~m}$. Comparison with the 2-dimensional data reveals these signals to be echo effects associated with the metal grille at floor level and the communion rail to the West of the grille. These therefore have no archaeological significance.

A number of substantial features of rectangular shape became visible in the western sector (and therefore below the main chancel floor) from 20ns onwards (Figure 7), confirming the detection of the Davenport family vault, and another similar feature on the South side of the church.

It is evident from comparing the Figures 6 and 7 that there is a physical separation between the Shakespeare family graves and the Davenport vault both as regards their respective depths and also from 
the gap in the East/West direction between the end of the graves in the upper chancel floor and the eastern edge of the vaults below the main chancel floor to the West. The $400 \mathrm{MHz}$ time slices do not show any feature which might bridge this gap.

\section{The first 1.5GHz survey: upper chancel floor (including ledger stones) and lower chancel floor}

The same areas were surveyed using a $1.5 \mathrm{GHz}$ transducer pair. The probing depth was set to $30 \mathrm{~ns}$, equivalent to a depth of $1.5 \mathrm{~m}$ at the calibrated transmission velocity, sampling along the line of travel was every $1.5 \mathrm{~cm}$ and successive lines were placed at $5 \mathrm{~cm}$ spacing in order to optimise data density consistently with the previous data set. As for the 400MHz survey, the area of the ledger stones and part of the area of the lower chancel were surveyed in full, allowing for the position of immovable church furniture.

Velocity calibration was carried out by curve fitting which confirmed the findings of the $400 \mathrm{MHz}$ survey i.e. dry conditions and a transmission velocity of $0.1 \mathrm{~m} / \mathrm{ns}$. All 2-dimensional data is displayed North to South from left to right and all 3-dimensional data is oriented so that East is at the top of the image. Data processing has been limited to elimination of Tzero, an overall background removal, the addition of exponential time based gain and the application of a de-wow filter. The de-wow filter was found to be more useful than a bandpass filter in clearing unwanted frequencies from the data, probably due to the necessity to preserve the higher end of the frequency band in a relatively lossy environment.

The data shows a heavy degree of ringing but also confirms the existence of a line of graves and other subsurface structures, at different depths but all close to the ground surface (Figure 8). The patterning changes as the survey lines move to the West (right to left in Figure 8) but there is a clear delineation of the first two graves, centred on $\mathrm{x}=-1.9 \mathrm{~m}$ and $\mathrm{x}=-0.65 \mathrm{~m}$ and another narrow feature directly between the two ("A" in Figure 8). The plaque commemorating Ann Hathaway is fixed to her ledger stone, directly above the first of these graves. There is no explicit memorial to William Shakespeare but the curse stone lies directly over this second grave. The next three graves appear to lie slightly deeper than the first two and to be partially covered by an upper uniform boundary on the evidence of the data to the West (rhs of Figure 8). The strong signals below $1.2 \mathrm{~m}$ are echo effects and should be ignored.

From Figure 8, this possible upper boundary suggests that the Shakespeare family graves (Nos 1 to 5 inclusive) may lie at approximately the same depth. There are double layer signals above the first two graves showing classic reversal of polarity from the upper to the lower. This is particularly clear in the second of the two radar plots in Figure 8. Reversal of polarity normally indicates the top and bottom of a homogenous material. However, in this case, this potential feature is not real, as both the change in signal strength and the apparent reversal of polarity are not features of the original raw data, unlike the equivalent fainter line in the left hand radargram which does correspond. The apparent increase in 
signal amplitude and the polarity is due to a localised effect of the overall background removal. The upper line over the three graves therefore has to be discounted for interpretative purposes. As will be seen from figures 3 and 12 , the upper boundary does not appear in either the $400 \mathrm{MHz}$ or the $4 \mathrm{GHz}$ data. Although, in the case of the former this could be due to the wavelength being too large for a small feature, the same would not be true of the $4 \mathrm{GHz}$ data. The middle three graves therefore lie deeper than the first two (cf Figure 8 rhs). As one might expect for a burial, these lower interfaces, presumably between the air and any remaining grave contents, are irregularly shaped.

Moving on to the lower chancel floor, the evidence of a much more cluttered subsurface, including substantial ringing, is clear (Figure 9). Survey line 34 (to the left in Figure 9) shows evidence of an arched structure of radius c. $1.5 \mathrm{~m}$, close to the surface, towards the end of the trace i.e. on the South side of the Chancel where the $400 \mathrm{MHz}$ data suggested that another vault was present. The known location of the Davenport tomb is clearly visible on the North (left) side of W60 at $(-0.15,0.38)$ from two large double hyperbolas, the upper one of which has a radius of c. $1 \mathrm{~m}$ and the lower of which appears to be composed of several discrete facets. These data demonstrate that the Shakespeare family graves are shallower and of a much sim- pler construction and therefore imply that a major family vault does not exist for the Shakespeare family.

Time slices were extracted from the 3-dimensional data set on the basis of changing signal patterning in a similar manner to the $400 \mathrm{MHz}$ data set. The white line towards the bottom of each time slice has been inserted to separate out the data from the area of the upper Chancel floor and the limited amount of data collected from the steps and the lower chancel floor. The width of this line is not an accurate reflection of the distance. In the commentary and discussion which follows, reference is only made to the data from the area of the ledger stones since this was the principal purpose of the survey. However the data does show evidence of the Davenport family tomb.

By $2.9 \mathrm{~ns}$ or c. $15 \mathrm{~cm}$ depth, there is a clear outline of an air gap in both Ann Hathaway and William Shakespeare's presumed burial locations, marked ' 1 ' and 2' respectively in Figure 9. As expected, these two graves have an East/West orientation. Neither grave appears to be full sized at this depth although this is difficult to judge in the case of Ann Hathaway's given that the strong signal is marking an air gap rather than contents. William Shakespeare's, on the other hand, appears to occupy the eastern end of the upper chancel floor only.

There is a thin rectangular feature lying between these two graves, marked ' $\mathrm{A}$ ' in the time slice and an additional rectangular feature with a North/South orientation to the West of the WS grave and the dividing feature, marked ' $\mathrm{B}$ ' in the time slice. Feature B is unusual not only in its orientation but also because it has an oddly shaped addition at its Northend, extending into the area of Ann Hathaway's grave. Although it might be tempting to postulate this as a young child's grave on the basis of its size and shape, this is 
extremely unlikely since there is currently no known Christian grave beneath a church floor in the UK lying in any other orientation than East/West (Rodwell, pers comm).

Feature ' $\mathrm{C}$ ' in the time slicealso lies along a North/South axis but appears to form part of a longer linear feature across much of the chancel, at least towards the South. This feature is made up of a solid block of strong signal which is likely to indicate an air gap followed towards the South by more randomly shaped areas of strong signal, all of which lie within the bounds of this same linear feature. Air gaps 6 and 7 represent the two graves to the South of the Shakespeare family and may therefore be ignored for the purposes of this paper.

Initially there was some concern, given that the patterning of the subsurface voids reflected the layout of the ledger stones on the floor above, that this might represent ringing. This is not the case, however, since ringing would reproduce all of the graves at the same level. This suggests that the current floor, known to have been re-laid in the $19^{\text {th }}$ century reflects the shallow archaeology beneath, presumably in defer- ence to what was thought to have been found at that time. By $5 \mathrm{~ns}$ or $25 \mathrm{~cm}$ depth, the remaining Shakespeare family graves are visible as are the two graves to the South of them (Figure 11).

The first four Shakespeare family graves are numbered 1 to 4 inclusive in Figure 11. Susanna Shakespeare's grave, number 5 is faintly visible between these graves and the non-Shakespearean graves (6 and 7). Feature 'A' now forms a thin well-defined line from the East end of the survey westwards towards linear feature ' $\mathrm{D}$ '. These appear to be brick walls. The patterning of linear features formed from randomly shaped small strong signal returns represents voids from the shaping of the brick and possible delamination in the mortar and has been observed elsewhere both within church monuments which are typi- cally formed of brick inside and in burial vaults (cf Utsi, 2008). This makes intrinsic sense in that brick construction is commonly used in this area of Warwickshire in the $17^{\text {th }}$ century.

Taken together, the two features indicate a designated burial area for the Shakespeare family from feature ' 2 ' up to but not including feature ' 7 '. This is slightly surprising given that feature 6 is not a Shakespeare family grave. The line of four graves represented by features 3 to 6 inclusive (including the one to the South of Susanna Shakespeare's) end at the same western extremity, some $35 \mathrm{~cm}$ to $40 \mathrm{~cm}$ away from brick wall ' $\mathrm{D}$ '. The continuity implied by the pattern in the time slice suggests a constructed lining of some sort to the burial area outlined by the brickwork.

Although Feature '2', the grave lying beneath the stone with the curse inscribed, still appears to be truncated relative to the graves to the South, its South West corner could potentially be in alignment with grave 1 (Ann Hathaway's) although there appears to be anomalous material further to the West of the latter, consistent with the existence of the remains of an earlier brick wall. It is difficult to be completely sure of the extent of graves 1 and 2 due to the irregular patterning of strong signals suggesting both air 
gaps (black) and potential contents (white/grey). However, all of the graves appear to respect the line formed by possible truncated wall ' $\mathrm{C}$ ' (Figure 10). At the lower level probable brick wall ' $\mathrm{D}$ ' also respects the line of feature $C$ (Figure 11). Comparison of Figure 10 with Figure 11 suggests that the materials used for feature $\mathrm{C}$ may not be the same in the area to the West of graves 3 to 6 as has been used for the ends of graves 1 and 2 .

\section{The first 4GHz survey: upper chancel floor (including ledger stones)}

The shallow depth of the Shakespeare family graves implied that it would be possible to use a very high frequency radar to scan and potentially improve target definition. The $4 \mathrm{GHz}$ antenna was therefore used to survey the upper Chancel floor, including the ledger stones. Since the graves of interest all lay beneath this floor, it was not consid- ered necessary to extend the survey into the lower Chancel floor.

A $4 \mathrm{GHz}$ antenna operating in dry soil has a wavelength of c. $2.5 \mathrm{~cm}$ which allows for the detection of very small objects, potentially as little as $10 \%$ of wavelength (Utsi, 2014). The purpose of using this frequency was to check on the possibility of grave goods or small metal objects which might indicate the presence of remains from the use of a wooden coffin. The change in fashion from burying in a shroud to using a wooden coffin occurs around the period of these burials (Sarah Tarlow, pers comm) and previous structural investigations outside Holy Trinity had yielded evidence of the use of shrouds at around the same time. The probing depth was set to the maximum of $10 \mathrm{~ns}$ (equivalent to $0.5 \mathrm{~m}$ at the calibrated transmission velocity), readings were taken every $0.78 \mathrm{~cm}$ along the line of travel of the radar and successive survey lines were recorded at $5 \mathrm{~cm}$ gaps. The data were processed by applying a de-wow filter, correcting for Tzero, applying a general background removal, the addition of exponential time based gain and a bandpass Butterworth filter to fit the transmission and reception parameters of the antennas used. The use of the two filters in processing is a reflection of the relative dominance of the lower end of the frequency spectrum in a very high frequency GPR deployed in a relatively lossy soil.

Velocity calibration was also carried out on this data set using curve fitting which confirmed the findings of the previous two surveys i.e. dry conditions and a transmission velocity of $0.1 \mathrm{~m} / \mathrm{ns}$. As for the previous data sets, all 2-dimensional data is displayed North to South from left to right and all 3dimensional data is oriented so that East is at the top of the image.

Figure 12 shows a radargram recorded across the ledger stones in the upper chancel floor (top image) and another recorded at the same level of floor but beyond the western edge of these graves, as defined by the $1.5 \mathrm{GHz}$ survey. As might be expected, the first of these shows very similar data to that of the $1.5 \mathrm{GHz}$ survey, a line of seven graves at differing levels with another feature between the first two graves to the 
North, lying slightly higher than the graves on either side. This corresponds to feature ' $\mathrm{A}$ ', thought to be a dividing wall. The 1836 measured drawing of the chancel floor shows a brick or tile divide between the graves of Ann and William Shakespeare. Interestingly the signal amplitude of the first two graves to the North and the two non-Shakespearean graves (numbers 6 and 7) is as strong as previously, confirming that these are likely to be air gaps. The central three graves, however, show no similar upper signals and reflect weaker signals suggesting either a lesser degree of difference and or less of an air gap. The potential feature overlying these graves, discussed, and dismissed in the discussion of the $1.5 \mathrm{GHz}$ survey results is not visible, confirming the conclusion above that this is not a real archaeological feature. The underlying reduction in signal amplitude may also be related to the increase in electrical losses with the use of such a high frequency. Beyond the western edge of these graves, the 2-dimensional patterning is quite different (Figure 12, bottom image). There are a few objects as evidenced by hyperbolas in the subsurface to the North (left hand side) and even more in the southern section (right hand side). However, only those in the North have strong signal amplitude. Given the depth of these objects, the strong signal amplitude suggests that these may be metallic object. As for the previous surveys, the 2-dimensional data were formed into a 3-dimensional data set from which time slices were extracted on the basis of significant changes in patterning. Figure 13 shows the time slice extracted at c. $13 \mathrm{~cm}$ in which the outline of the North/South feature, 'B' previously identified in the $1.5 \mathrm{GHz}$ survey, is visible. Parts of Ann Hathaway's and William Shakespeare's presumed graves are also visible (graves 1 and 2 respectively). The mix of dark and light within the boundaries of the grave associated with William suggests that there is material within this grave whether this is soil, human remains or a mixture of both. There is no way in which bones can be distinguished from their surrounding soil after this length of time since the post mortem interaction between bones and soil will result in their electro- magnetic differences being infinitesimally small. The air gap within Ann Hathaway's grave shows a similarly broken patterning in the middle section of the grave. The East end is entirely black, presumably indicating an air gap and the West end is entirely light coloured, indicating continuity with the environment and therefore suggestive of the presence of material such as soil and possibly human remains.

The faint outlines at the western end of each of the three middle graves (numbers 3 to 5 inclusive) are reflections of the air gaps formed by the imprint of coats of arms in the stone at floor level. These are very small indents but the short wavelength of the $4 \mathrm{GHz}$ radar is sufficient to measure these tiny voids and set up echo effects where the magnitude of the signal returns from the subsurface data is not great enough to mask them.

A little deeper into the graves, two small rectangular features become visible within the northernmost grave, presumed to be that of Ann Hathaway (Figure 14). The smaller rectangle, to the East, is an echo effect from the brass name plaque at floor level. The slightly larger, feature ' $E$ ' is not due to ringing. The remaining three centrally placed graves, nos 3 to 5 inclusive become visible between $4.3 \mathrm{~ns}$ and $4.6 \mathrm{~ns}$ (Figure 15). The variation in signal strength indicates the formation of air gaps in parts of each grave 
(black) and extant material in the remainder (grey/white).

\section{The surveys of the lower altar step}

On a first analysis, Figures $10(1.5 \mathrm{GHz}$ data) and $13(4 \mathrm{GHz}$ data) suggest that the length of both of the two most northerly graves (numbers 1 and 2) is shorter than that of the remaining graves in alignment with them i.e. those of Thomas Nash, John Hall and his wife Susanna Shakespeare and the two non-Shakespearean family graves, at least at the shallower level. Since the altar step is known to date from the $19^{\text {th }}$ century, it was initially presumed that these first two graves must extend eastwards beneath the lower altar step. Accordingly the survey was extended into this area.

Both the $400 \mathrm{MHz}$ and the $1.5 \mathrm{GHz}$ antennas were used for this second survey. The $4 \mathrm{GHz}$ was not used since the additional height of the step (c. $20 \mathrm{~cm}$ ) would limit the depth range of the antenna, a maximum of $50 \mathrm{~cm}$ under ideal conditions, into the area of interest. The survey reference lines used were an extension of those used in the first survey and the survey parameters used for each antenna were identical to the preliminary ones. The first two survey lines of 2-dimensional data from the $400 \mathrm{MHz}$ survey, collected along the western edge of this area suggest the presence of two simple shallow graves, centred on $\mathrm{x}=-0.65 \mathrm{~m}$ and $\mathrm{x}=1.4 \mathrm{~m}$ (Figure 16). These positions correspond to the location of the graves of William Shakespeare and John Hall respectively (graves 2 and 4) in the area of the ledger stones (Figure 16 right hand side). However, beneath the ledger stones, these two graves are not adjacent to one another as Thomas Nash's lies in between. Also they do not appear to lie at the same depth, Shakespeare's (grave 2) being shallower than Hall's (grave 4). From the third survey line eastwards there is no evidence of central disturbance consistent with a grave (Figure 16, left hand side). This implies that these features extend towards the eastern end of the church rather than the West and are therefore not likely to be extensions of the graves beneath the upper chancel floor.

The data from all of the survey lines of the lower altar step indicates the presence of more substantial graves in the South of this area, which, on the basis of complexity and depth do not match the Shakespeare family graves in the upper chancel (Figure 16). The evidence of arched surfaces and echo effects is consistent with the data from the lower chancel floor so that these burials seem more likely to be contained within vaults, rather than the simple burials of the Shakespeare family. There is one similar area to the North, visible in the first two survey lines only (cf right hand side of Figure 16). As this lies immediately adjacent to a large monument above ground it is likely to be a related feature. The 2dimensional data therefore suggests that there is no continuity between the simple shallow graves of the upper chancel floor and the burials beneath the lower altar step.

As expected the time slices reflect this patterning. The first time slice was extracted at $7.42 \mathrm{~ns}(\mathrm{c} .31 \mathrm{~cm})$ 
to correspond with the subsurface depth of Figure 6 , allowing for the additional $20 \mathrm{~cm}$ depth of the altar step above the ledger stones (Figure 17). At first sight this appears to support the idea of part of a substantial grave in the NW cornerand a line of graves running North/South in a similarmanner to Figure 6 with some additional strong signal patterning extending eastwards along the southern edge (Figure 17). However, it is difficult to determine the precise location of each grave, in spite of the close data sampling and there does not appear to be a correspondence of position with the graves below the upper chancel floor. Going deeper into the ground gives a different pattern i.e. the possibility of substantial graves, potentially vaults, in the NW and SW corners (Figure 18). These are clearly not related to the Shakespeare family graves both from their location within the chancel and the depths. In turn, this suggests that the apparently anomalous material visible at $7.42 \mathrm{~ns}$ is associated with the construction of the Victorian floor rather than a continuation of the graves to the West.

The improvement in target definition from using a $1.5 \mathrm{GHz}$ antenna resolves the issue of potential graves (Figure 19). The 2-dimensional data show substantial evidence for a formal burial in the NW corner of the lower altar step. The corner reflection visible in the subsurface is typically generated inside a cuboid structure such as a crypt, vault, or large stone container (cf Martinaud \& Frappa, 2004). This signal patterning is commonly found beneath the floor of large churches such as Westminster Abbey and usually associated with substantial graves of the $18^{\text {th }}$ and $19^{\text {th }}$ centuries (cf Figure 5 in which there are a number of similar examples). Although they are associated with air gaps within the subsurface, the typical transmission velocity is that of the surrounding ground. This signal confirms the previous suggestion that the substantial grave or vault in the NW corner is related to the above ground monument covering the tomb of Thomas Balsall and has no bearing on the Shakespeare family graves. To the SW, the deep areas of disturbance suggest either more complicated structures or, possibly, multiple burials which are also unconnected to the Shakespeare family graves (Figure 19). The central area, however, is visibly free from such disturbance. It appears to consist of areas of careful levelling, particularly in the areas perceived by the $400 \mathrm{MHz}$ antenna as being anomalous. This is consistent with the relative target definition of the two antennas. It appears highly likely that the area contained burials at some point in its history but that these sections of ground have been levelled, possibly compacted to some extent, presumably in connection with the laying of the floor and, more specifically the construction of the current altar step. There does not appear to be any continuity between the graves within the area of the upper chancel floor into the area below the lower altar step. The time slices confirm the lack of continuity between the graves beneath the area of the ledger stones and those beneath the altar step. By c. $4 \mathrm{~ns}(\mathrm{c} .20 \mathrm{~cm})$, there is evidence for a separate shallow grave (numbered ' 8 ' in Figure 20). As this depth equates to the size of the step between the lower altar area and the ledger stones in the upper chancel floor, this grave is even shallower than those in the latter area. Although this grave aligns approximately with grave 6, the first grave to the South of the Shakespeare family graves, it is sufficiently large, the depth shallower and the alignment inexact enough, for this to be considered an independent grave. This time slice also illustrates a substantial 
grave in the NW corner together with an area of disturbance to the east of it ('F'). Since neither of these align with either William Shakespeare's or Ann Hathaway's grave, it is more likely that they are related to the large memorial covering the tomb of Thomas Balsall located on the north chancel wall of the altar step (which is therefore blank in the data). Although the remainder of the western edge could relate to graves, the signals do not correspond with the patterning of the graves and it is therefore more likely that they relate, as suggested above, to the construction of the present floor. The last traces of the very shallow grave are visible around $7 \mathrm{~ns}(35 \mathrm{~cm})$ which corresponds with the depth of the Shakespeare family graves beneath the ledger stones (Figure 21, cfFigure 10). It is clear from this time slice that there is no continuity in graves between the two areas. The substantial grave in the NW corner appears to be associated with the grave monument to the North and there are furthersimilar features in the South of the area. The signal patterning along the West side is much more diffuse and there is no continuation visible from either of the graves presumed to be those of Ann Hathaway or William Shakespeare (graves 1 and 2).

\section{Discussion}

It is noticeable that the 2-dimensional data contains a level of ringing consistent with a soil which is not entirely suited to GPR investigation. It is likely that this is due to the soil response and potentially any water content. Although no soil analysis was possible, the data are consistent with a soil with partial clay content and in which the level of the groundwater rises, especially in winter. At the time of the surveys, however, the calibrated transmission velocity indicates a dry soil and this result was consistent over the three frequencies used as well as with the observed level of the nearby river.

The processed data are consistent with the raw data in the features that they show with the exception of the strength and apparent change in polarity of a single line within the $1.5 \mathrm{GHz}$ data (Figure 8, left hand side). This indicates that the features are genuine and represent what remains of archaeological features. Given the position and shape of these features within the time slices, the principal features in the area of the upper chancel represent simple shallow graves. Longer linear features have the appearance of walls, some of which are of brick construction. It is not uncommon for burials beneath church floors to appear relatively haphazard in their positions, intercutting of graves being a common finding (Rodwell, 2012). The fact that the Shakespeare graves exist in an unbroken line is not merely a reflection of William Shakespeare's investment in Chancel privileges in 1605 but also implies immense and enduring respect for him and for his family (Holy Trinity, 2016). It is also not common practice for the position of a memorial stone to mark the exact position of the burial although this does sometimes happen. It is more usual for there to be far fewer memorials than burials and for the memorials to be at a position within the church which may not be related to the actual burial position (Rodwell, 2012). The first questions therefore have to be a) is William Shakespeare buried in one of the graves beneath a ledger stone in the area of the upper Chancel floor and b) does grave 2, the one with 
the inscribed curse, cover, as has been assumed, the relevant grave? Since the contemporary church burial register records the burial, it seems very likely that William Shakespeare was buried in the first of the Shakespeare family graves dug beneath the chancel, whichever of the detected graves that may be. The surprising result of the GPR survey is that there is no evidence for even a moderately sized family vault, the deceased having been buried instead in a series of shallow graves.

The apparent irregularity of the grave outlines in the time slices is not due to the slight unevenness in the current floor surface. This, coupled with the signal strength, indicating a material very different from the stone above, and the variation in pattern across the outline of the grave strongly suggests the presence of air in each of the burial positions (cf Utsi, 2006; Utsi, 2012). From the comparison of the minimalistic shallow graves beneath the ledger stones with the larger later graves to the North and South of the upper chancel and the lower altar step, the Shakespeare family graves appear to be simple constructions rather than individual small vaults. Their detection rests not on the grave contents but on the accumulation of small irregular air gaps at their top boundaries, implying that these graves had been backfilled at the time of burial. This interpretation is not only consistent with the data from the three surveys from the upper chancel floor but also goes some way to explaining the previous failure to detect their existence. Target definition depends directly on the wavelength of the antenna used and the minimum size of any target needs to be at least $10 \%$ of the wavelength but also over one half of a wavelength's distance from any similar feature(Daniels, 2004). The wavelength in dry soil of a $250 \mathrm{MHz}$ GPR is $40 \mathrm{~cm}$, that of a $400 \mathrm{MHz}$ system $25 \mathrm{~cm}$. For a $1.5 \mathrm{GHz}$ GPR the equivalent wavelength is c. $6.7 \mathrm{~cm}$ and, for a $4 \mathrm{GHz}$ system, $2.5 \mathrm{~cm}$. Since the data indicates an irreg- ularly shaped air gap over the top of each grave rather than an upper and lower level, these are small features, just detectable by the $400 \mathrm{MHz}$ antenna, better defined by the higher frequencies, $1.5 \mathrm{GHz}$ and $4 \mathrm{GHz}$ but too small for the lower frequency system used earlier.

The burial area is bounded by feature ' $\mathrm{D}$ ', probably abrick wall, to the West, but the ends of the graves have another common boundary in feature ' $\mathrm{C}$ ', a more homogeneous material, inside this wall. If the inscriptions on the ledger stones are taken to be accurate the burials did not take place in a systematic fashion even though the graves are clearly aligned not only with each other but also with the ledger stones above them. From the dates of death, the burial sequence of the graves from North to South is 2, 1, 4, 3, 5 which, while not impossible, is odd. Bearman (2013) eludes to a number of theories behind the odd sequencing including a) the stones belonging to Hall and Nash have been swapped so the Hall stone ultimately adjoined his widow's, and b) a gap was left adjacent to William's stone which was intended for Susanna, but the untimely death of Nash altered this plan. There must have been a clear demarcation of each grave post burial for these graves not to intercut one another. The only internal boundary is the thin wall dividing graves 1 and 2, feature ' $A$ ' which corresponds to historical mapping which suggests that Ann Hathaway's gravewas divided from that of her husband (Bearman, 2013). 
As for the grave presumed to be that of William Shakespeare (grave 2) this appears at first sight to be unnaturally short since, neither it nor any of the other family graves appear to extend into the area beneath the altar step. From figures 10 and 13 this grave does not appear large enough to contain an adult male and the evidence could potentially be construed, as has been suggested, that the grave does not contain aburial. This seems unlikely given the apparent existence of a subsurface air gap above material that is both mixed but also approaches the soil beneath in its relative permittivity (cf Figures 8 and 12). In addition, Figure 6 from the $400 \mathrm{MHz}$ data suggests that all of the graves are of equal length. It is therefore worth re-examining Figure 11 from the $1.5 \mathrm{GHz}$ data. This time slice, extracted approximately $10 \mathrm{~cm}$ below the initial definition of the air gaps marking the grave positions (Figure 10). indicates that, although there is a difference in the density of the strong signal reflections, both William's and Ann's graves appear to reach the same position at their West ends as the other graves in the sequence at the lower level. If the reasonable interpretation of the areas of strong signals as air gaps is accepted thenit would appear that there are mixed materials at the western end and undisturbed material in the eastern half(Figure 11).

All of the graves appear to be shallow but the first two lie much closer to the current floor level than expected. It is known that the chancel floor required repair on more than one occasion in the past and that the chancel was restored and reworked on a number of occasions (Bearman, 2013), including twice in the $19^{\text {th }}$ century when it was common practice to re-arrange the layout of a church to fit what was perceived as the appropriate pattern. Although there are no records indicating that the series of Shakespeare family graves were uncovered during the relaying of the floor, the GPR data raises the suspicion that the current positions of the ledger stones and also the western limit of the lower altar step may have been matched to that of the archaeological remains beneath. The alternative, that the signal patterning reflects the layout above, is not a possibility since although the outline areas match, the internal subsurface patterning does not.

Taken together these observations focus attention on the area of the anomalous North/South feature. Assuming that the area of very strong signal in the upper level of feature ' $\mathrm{B}$ ' is also a reflection of air content, this implies that the narrow band of white surrounding the feature is a man-made construction, some form of box made either of stone or possibly of brick. Figure 10 shows that this construction cuts across the full western end of Shakespeare's grave, also across the wall dividing his grave from that of his wife and ends in a rather strange small scoop shape in the SW corner of her grave. There is no similar feature in any of the other graves that lie beneath the ledger stones. The most obvious reason for this construction is as some sort of repair to the church floor, compensating for a surface irregularity caused by movement or even removal of material from the subsurface. This implies that, in spite of the curse inscribed on the floor, William Shakespeare's grave has been opened at some point in the past. If this is the case, then it is very likely that the small scoop shape visible in the SW corner Ann Hathaway's grave (grave 1) may reflect damage which occurred in trying to lift the original floor stones when the grave was opened. If damage was caused at the same time to the brickwork, this would also explain why the void cuts across the dividing wall (feature ' $\mathrm{A}$ ' in Figure 10). 
One plausible account of grave disturbance was published in Argosy magazine in 1879 entitled 'How Shakespeare's skull was stolen' (A Warwickshire Man, 1879). This publication, often dismissed as gothic fiction, recounts events of 1794 when a scheme to steal the skull was enacted by a group of grave robbers under the direction of Dr Frank Chambers. This account includes a great amount of detail including descriptions of places, events, and people - with documentary research confirming the accuracy of these inclusions. What could not be confirmed is the details of the theft itself. The Shakespeare ledger stone was carefully lifted by the robbers after breaking into the church to reveal previously disturbed grave fill and debris. After careful excavation at the western end, the robbers recovered a skull at a depth just under three feet. This fact seems important as the common belief at the time was that Shakespeare was either buried much deeper than this or that he was buried in a large family vault or crypt. More importantly, the GPR results do in fact support the final elements of this publication, namely the existence of a shallow, simple burial beneath Shakespeare's ledger stone. If the Argosy article recounts actual events rather than a piece of gothic fiction, and previous disturbance to Shakespeare's grave had occurred even prior to this, then these could well explain the necessity to repair the chancel floor at this location in such a significant way. Also, this points to the uncomfortable fact that perhaps the skull of the world's most famous playwright is not with the rest of his remains and is in fact missing. Obviously it is not possible to detect the presence or absence of the skull itself from the radar results since any remaining bone will have taken on the electromagnetic properties of the surrounding soil and human remains are therefore only detectable by the relative position of associated artefacts (cf Utsi, 2006). The evidence of intrusion into the western end of the grave is interesting in the light of this particular account.

\section{Susanna Shakespeare's grave}

Historical sources suggest that Susanna Shakespeare's grave (no 5) may have been disturbed to make way for the burial of Richard Watts in 1691, as a stone bearing his name is in this location on the Chancel floor plan of 1836. Although it is impossible for any of the GPR data to substantiate or disprove this theory, it is worth comparing the evidence of the ground above Susanna's grave with those of her husband John Hall and Thomas Nash as illustrated in Figure 12. Taking the evidence from Susanna's grave first, there does appear to be an extra layer within the grave which might indicate the addition of another burial(Figure 12). If so, the entire grave has been compressed to some extent since there is no point at which it is covered by a full air gap and the signal strength which determines its position and outline is considerably less than either Hall's or Nash's (Figure 10). Although not definitive, this could potentially be construed as post depositional interference in this grave. The evidence from the surveys of the upper chancelfloor rules out a number of stories associated with Shakespeare's grave. The inconsistency of the accounts of reaching Shakespeare's tomb from the interior of the Davenport vault is unsurprising given that the survey has shown that not only is the Davenport vault lower in depth but 
also that there is a clear barrier in between the two burial sites (Figures 6 and 10). It is reasonably certain that, with the exception of Susanna Shakespeare (grave no 5), no-one else has been buried subsequently within the area of the Shakespeare family graves. There is insufficient room for an interment above the shallow graves and the survey data also illustrate that the ground immediately below does not contain any evidence of disturbance. This rules out the story of burial 17 feet $(5.18 \mathrm{~m})$ below the surface. Although it is possible that the traces of a very deep burial could have been removed over the centuries as groundwater periodically rose, the nature of the burials that can be seen are suggestive of the relative time period, making this a less likely proposition. It is clear that the Shakespeare graves are all surprisingly shallow although the precise depth of each burial varies, with the later ones appearing to be slightly deeper than the first two. What is also interesting are the features which are not present. Had the people buried in these graves been enclosed first in wooden coffins, it is unlikely that the coffins would have survived but very likely that the metalwork associated with the coffins (handles, plaques and nails) would remain. None of the data has revealed any potential metalwork except in the areas of later burials towards the West and possibly also in the South (cf Figure 12). This was only detectable by the $4 \mathrm{GHz}$ antenna which implies that these signals represent small objects. One possibility is that the whole area has been searched for metal in the past, a known practice in order to obtain the financial value of the recycled material. However, there is no evidence for one or more searches of this nature beyond the unusual absence of metal beneath the eastern end of the upper chancel floor and its scarcity beneath the western end of the same floor. The implication is therefore that the Shakespeare family were buried in shrouds, still a common practice at the time of their respective interments (Tarlow, pers comm).

Nor do there appear to be any grave goods associated with the burials with the possible exception of one item within Ann Hathaway's grave which was thin enough to be detectable only at very high frequency (Figure 14). Although potentially this could be metal, based on the high signal amplitude, there is no associated ringing, unlike the metal plaque on the surface and it appears to be possible for the radar to be able to detect lower down in this position. This may therefore be a thin container made of some other material with the strong signal being created by the reflection from a thin air gap within. Although the research team would have welcomed the opportunity to verify the conclusions by use of an endoscope, this has not been permitted as the Church authorities consider that even a minor intrusion would disrespect the curse inscription.

\section{Conclusions}

The primary conclusion of this investigation is that selection of antenna frequency is extremely important in the GPR investigation of historical buildings. In this example, although it was possible to detect the graves using a $400 \mathrm{MHz}$ antenna, the majority of these features were shallower than expected so that it was possible to gain better definition was by using high and very high frequency antennas. Had only 
one frequency been used, the data obtained would have been limited. Unfortunately unless the depth and size of targets and soil/groundwater information is available in advance, there is a risk of nondetection if, for example, the wavelength is too large for the size of the targets. Comparison of the data obtained using different frequencies was also critical to understanding several aspects of this project. For example, the apparent absence of any metal could not have been tested without the very high frequency, determining the length of the graves relies on being able to compare the $400 \mathrm{MHz}$ and $1.5 \mathrm{GHz}$ data as does the resolution of data from beneath the altar step. Understanding the apparent intrusion into graves 1 and 2, those associated with William Shakespeare and his wife, has also depended on being able to compare the three data sets. These surveys also show the advantages of applying close traverse spacing, to target definition, especially when the targets are several centuries old and relatively small in size, at least in their vertical dimensions.

The results of the GPR investigation have laid to rest a number of historical myths about the Shakespeare graves. The data are consistent with a historical tale which was originally thought unlikely since the data confirm that the grave thought to be that of William Shakespeare has been partially cut across by another feature, presumably in an attempt to restore the stability of the floor. The data also show that the Shakespeare family was not buried in a traditional vault, although some of the area is delineated by brickwork but in a discrete line of simple shallow graves. The use of a very high frequency antenna has allowed the deduction that burial for each of the five members of the family was in a shroud, not in a coffin from the absence of small metal artefacts in the area of their interment. Comparison of the data for the central three graves suggests that there may be foundation to the story of Susanna Shakespeare's grave being disturbed even if it is not possible to conclude whether she was exhumed and subsequently reinterred elsewhere. The details of this investigation have contributed interesting material to the on-going study of William Shakespeare's life and death.

\section{ACKNOWLEDGEMENTS}

The authors would like to thank Professor Rodwell and the Dean and Chapter of Westminster Abbey for permission to use the data in Figure 5 for comparative purposes. The project would not have been possible without the continued support of Holy Trinity Church, particularly Reverend Paul Taylor, Archdeacon of Oxford Venerable Martin Gorick, and Church Warden Mike Warrillow. Thanks also to Channel 4, the staff from Arrow Media, and to Bob Bearman for their help and support during the project.

\section{REFERENCES}

Baldwin,E. (2013). GPR Survey of the Shakespeare family Ledger Stones.

Unpublished technical report by the University of Birmingham.

Barone, P. M., Di Matteo, A., Graziano, F., Mattei, E., \& Pettinelli, E. (2010). GPR Application to the structural control of historical buildings: two case studies in Rome, Italy. Near Surface Geophysics, 8(5), 407-414.

Bavusi, M., Soldovieri, F., Piscitelli, S., Loperte, A., Vallianatos, F., \& Soupios, 
P. (2010). Ground penetrating radar and microwave tomography to evaluate the crack and joint geometry in historical buildings: some examples from Chania, Crete, Greece. Near Surface Geophysics, 8(5), 377-388.

Bearman, R. (2013). The Shakespeare Ledger Stones in Holy Trinity Church, Stratford-upon-Avon. Holy Trinity Church, Stratford: An unpublished documentary report for the Parochial Church Council.

Calia, A., Leucci, G., Masini, N., Matera, L., Persico, R., \& Sileo, M. (2012). Integrated prospecting in the Crypt of the Basilica of Saint Nicholas in Bari, Italy. Journal of Geophysics and Engineering, 9, 271-281.

Crayon, G. (1819-1820) Sketch Book of Geoffrey Crayon, Gent, vii, 65, London

Daniels, D. J. (2004). Ground Penetrating Radar 2nd Edition. London UK: The Institution of Electrical Engineers.

Drake, N. (1818). Shakespeariana Monthly Magazine: 1-8.

English Heritage (2008). Geophysical Survey in Archaeological Field Evalua- tion. Swindon, UK: English Heritage Publishing.

Gabellone, F., Leucci, G., Masini, N., Persico, R., Quarta, G., \& Grasso, F. (2013). Non-destructive prospecting and virtual reconstruction of the Chapel of the Holy Spirit in Lecce, Italy. Near Surface Geophysics, 11, 231238.

Harness W. (1844). Diary of William Harness. Unpublished

Holy Trinity Church website. (2016). http://www.stratford-upon-avon.org/ the-sanctuary.

Horsler, V., Gorick, V., \& Edmondson, P. (2010). Shakespeare's Church, A Parish for the World. London, UK: Third Millennium Publishing.

Leucci, G. (2002). Ground-Penetrating Radar Survey to Map the Location of Buried Structures under Two Churches. Archaeological Prospection, 9, 217-228.

Lorenzo, H., Hernández, M. C., \& Cuéllar, V. (2002). Selected Radar Images of Man-Made Underground Galleries. Archaeological Prospection, 9(1), 1-8.

Martinaud, M., \& Frappa, M. (2004). GPR signals for the understanding of the shape and filling of man-made underground masonry. Proceedings of the Tenth International Conference on Ground Penetrating Radar, II, 439-442.

Novo, A., Lorenzo, H., Rial, F. I., \& Solla, M. (2010). Three-Dimensional Ground-Penetrating Radar Strategies over an Indoor Archaeological Site: Convent of Santo Domingo (Lugo, Spain). Archaeological Prospection, 17, 213-222.

Rodwell, W. (2012). The Archaeology of Churches. Stroud, Gloucs, UK: Amberley Publishing.

Serbin, G., Or, D., \& Blumberg, D. G. (2001). Thermodi-electric Effects on Radar Backscattering from Wet Soils. IEEE Transactions on Geoscience and Remote Sensing, 39(4), 897-901.

Thomas AM, Metje N, Rogers CDF and Chapman DN. (2006). Ground Penetrating Radar Interpretation as a Function of Soil Response Complexity in Utility Mapping Proceedings of the $11^{\text {th }}$ International Conference on Ground Penetrating Radar, Ohio State University, Columbus, Ohio.

Utsi, E. (2006). Improving Definition: GPR Investigations at Westminster Abbey. In Proceedings of the 11th International Conference on Ground Penetrating Radar. Columbus Ohio: Ohio State University.

Utsi, E. (2008). The Villiers Street Chapel Burial Vaults: a Case Study in GPR Detection. In Proceedings of the $12^{\text {th }}$ International Conference on Ground Penetrating Radar. Birmingham: UK.

Utsi, E. (2012). The Shrine of Edward the Confessor: a Study in Multi-Frequency Investigation. Near Surface Geophysics, 10(1), 65-75.

Utsi, E. (2014). Target Resolution using Very High Frequency Ground Penetrating Radar. Proceedings of the Structural Faults and Repair Conference, Edinburgh, Scotland (CD).

Warwickshire Man (1879). How Shakespeare's Skull was stolen. Argosy Magazine, 1879. 


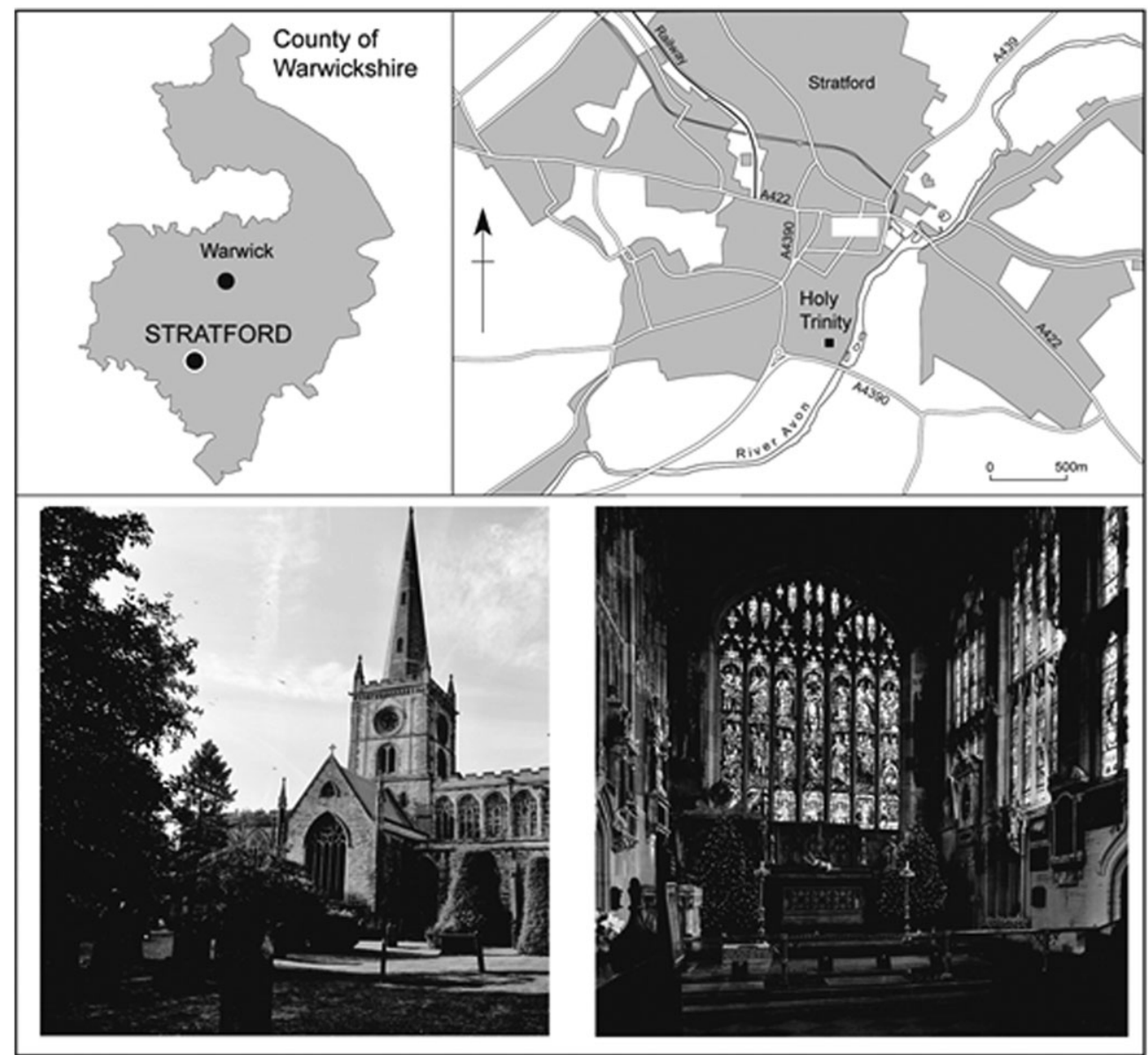

FIGURE 1 Location of Holy Trinity Church, Stratford-upon-Avon and photographs of the church exterior (left) and the chancel interior (right) 


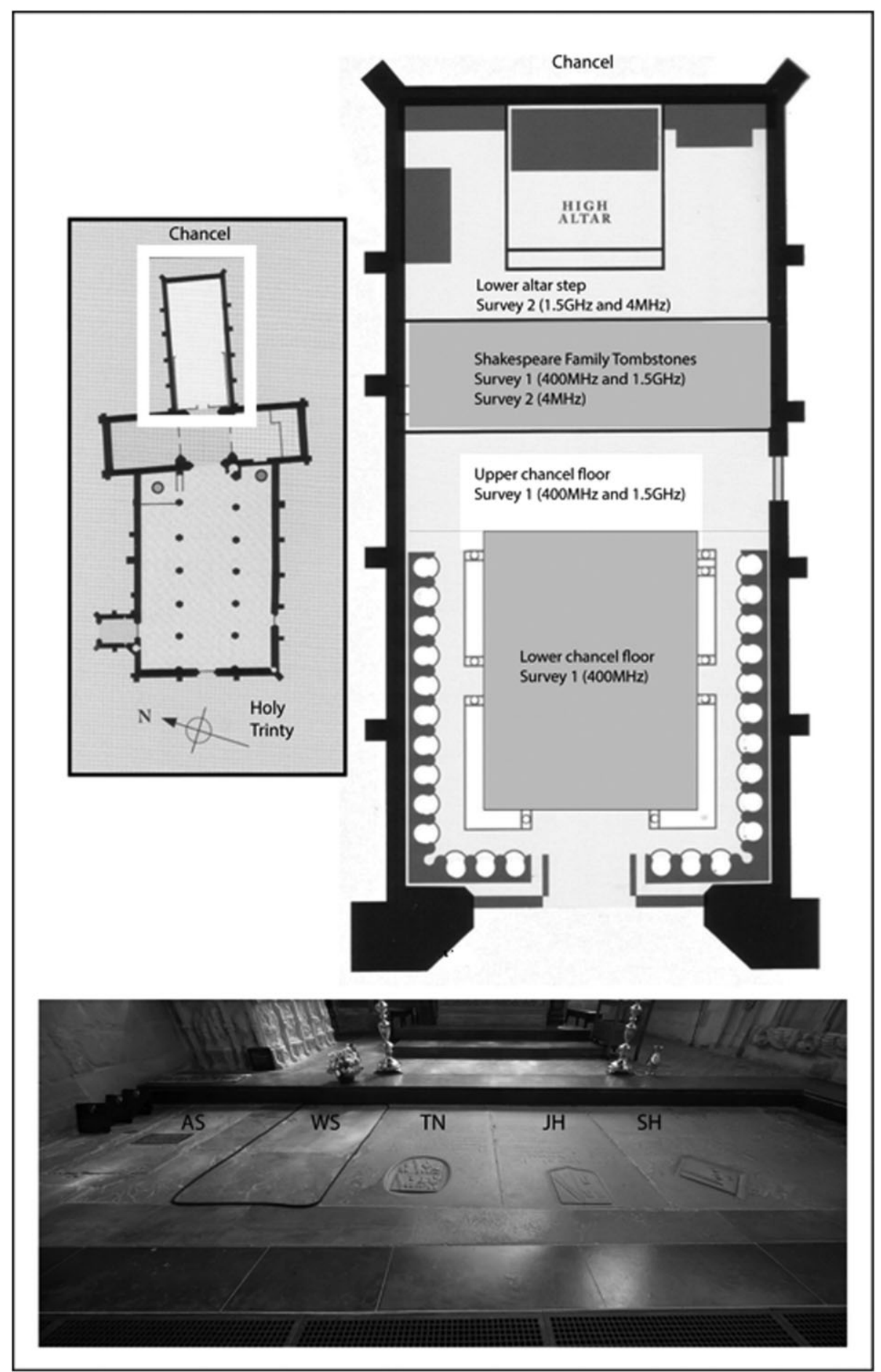

FIGURE 2 Plan of the Chancel showing the location of the chancel GPR surveys (top) and a photograph of the Shakespeare family ledger stones (bottom; AS, Ann Shakespeare, née Hathaway, WS, William Shakespeare, TN, Thomas Nash, JH, John Hall, SH, Susanna Hall née Shakespeare) 

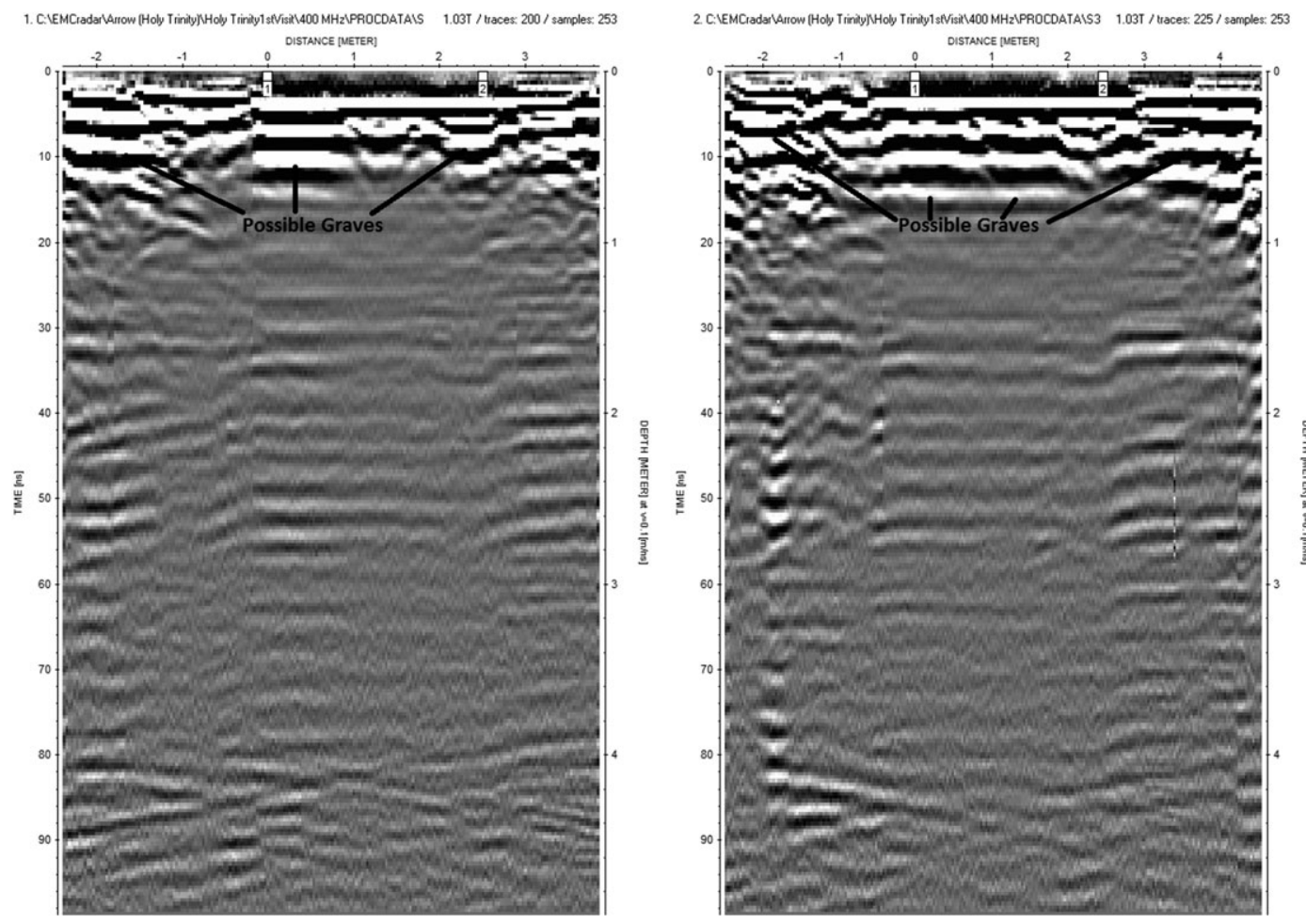

FIGURE 3 400MHz Survey lines S and S3 taken across the Shakespeare family ledger stones on the upper chancel floor showing signal responses consistent with air gaps close to the surface
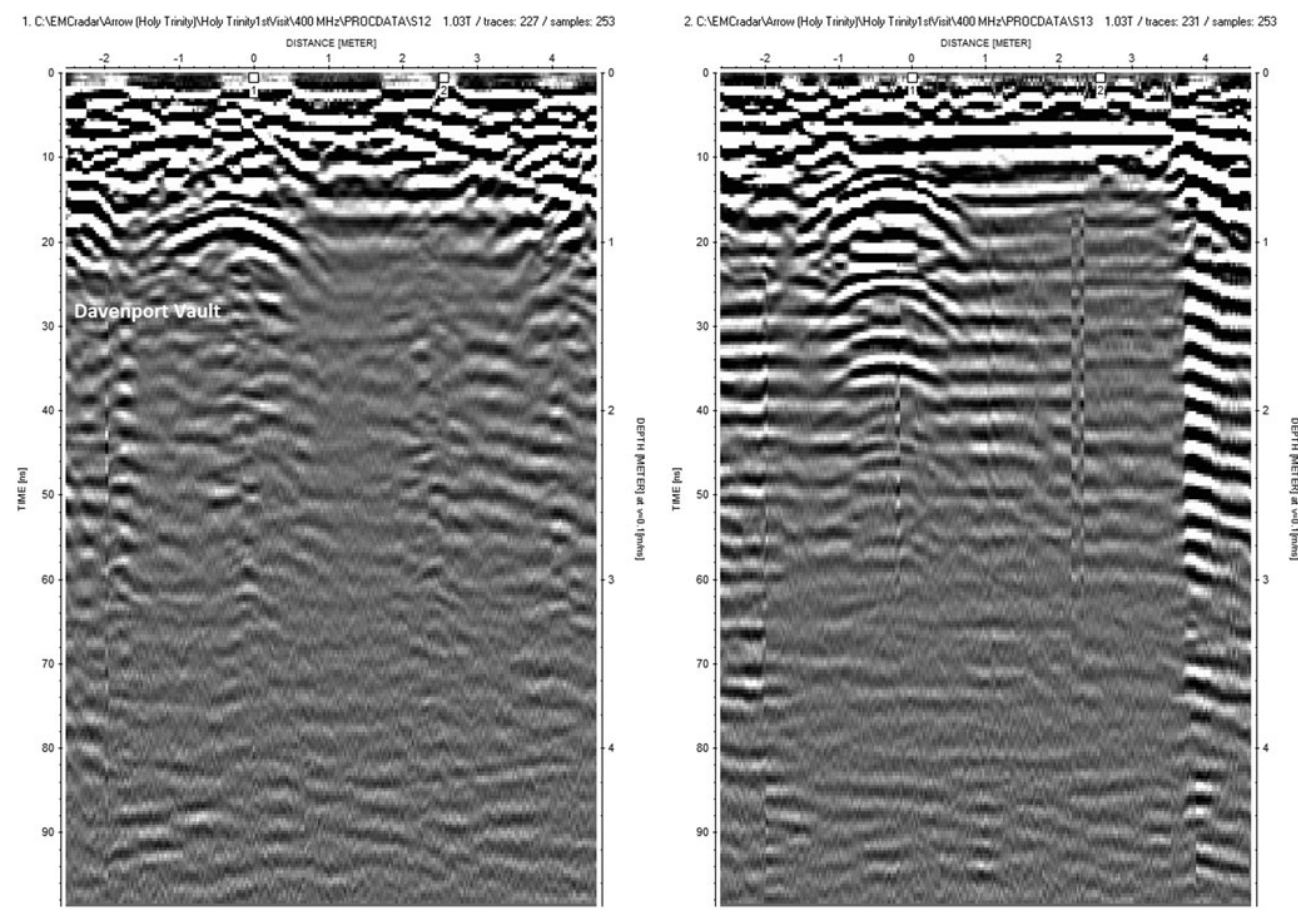

FICURE 4 400MHz Survey lines S12 and S13 from the lower chancel floor including the area above the Davenport family vault (Ihs) 


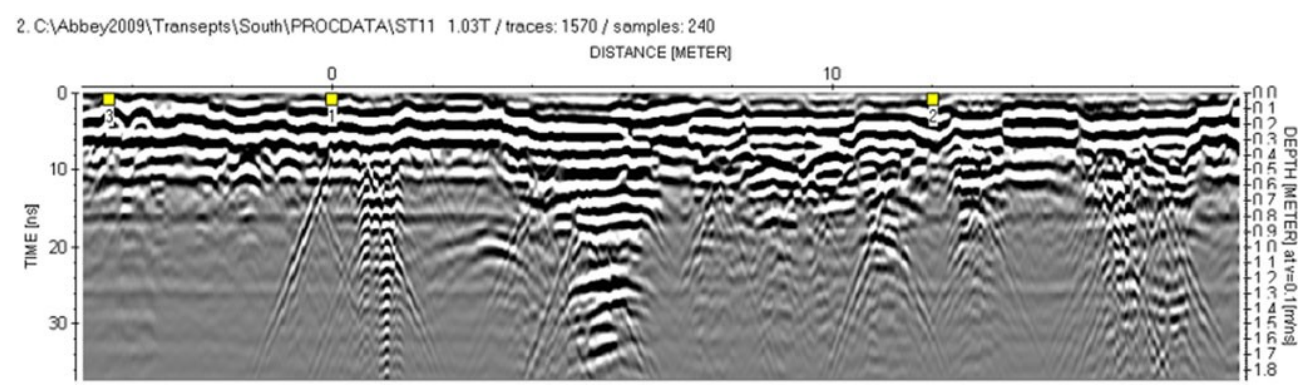

FIGURE 5 Comparative $400 \mathrm{MHz}$ data from Westminster Abbey showing a variety of grave evidence. [Colour figure can be viewed at wileyonlinelibrary.com]

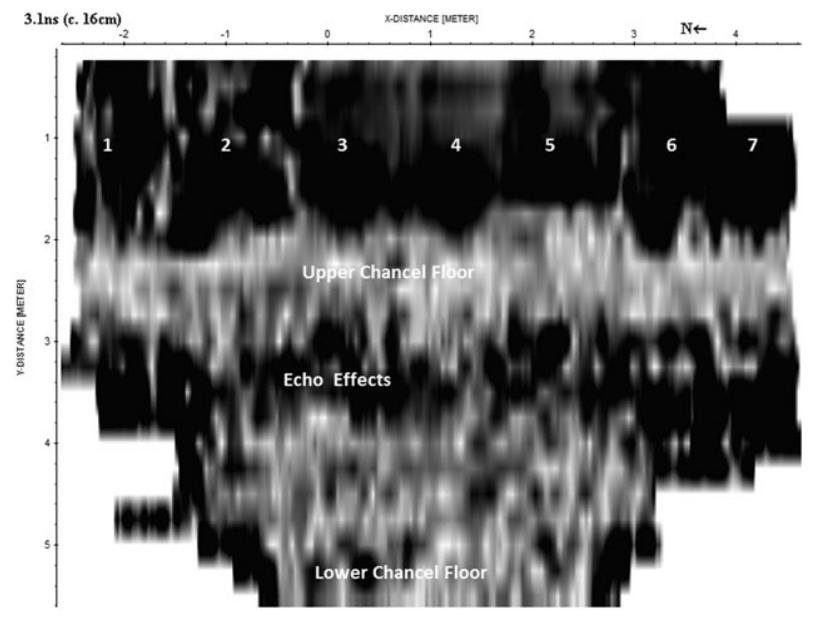

FIGURE $6400 \mathrm{MHz}$ Time Slice at $3.1 \mathrm{~ns}$ or c. $16 \mathrm{~cm}$ showing the outline of 7 potential graves, the first 5 of which correspond to the position of the Shakespeare family ledger stones

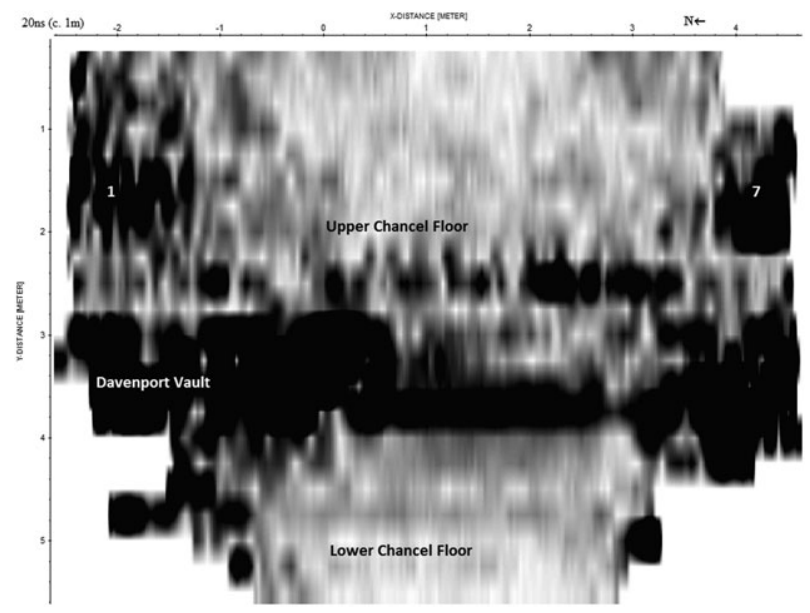

FIGURE 7 Time Slice at 20ns or $1 \mathrm{~m}$ showing the outline of the Davenport vault below the lower chancel floor and at least one other similar feature to the South 

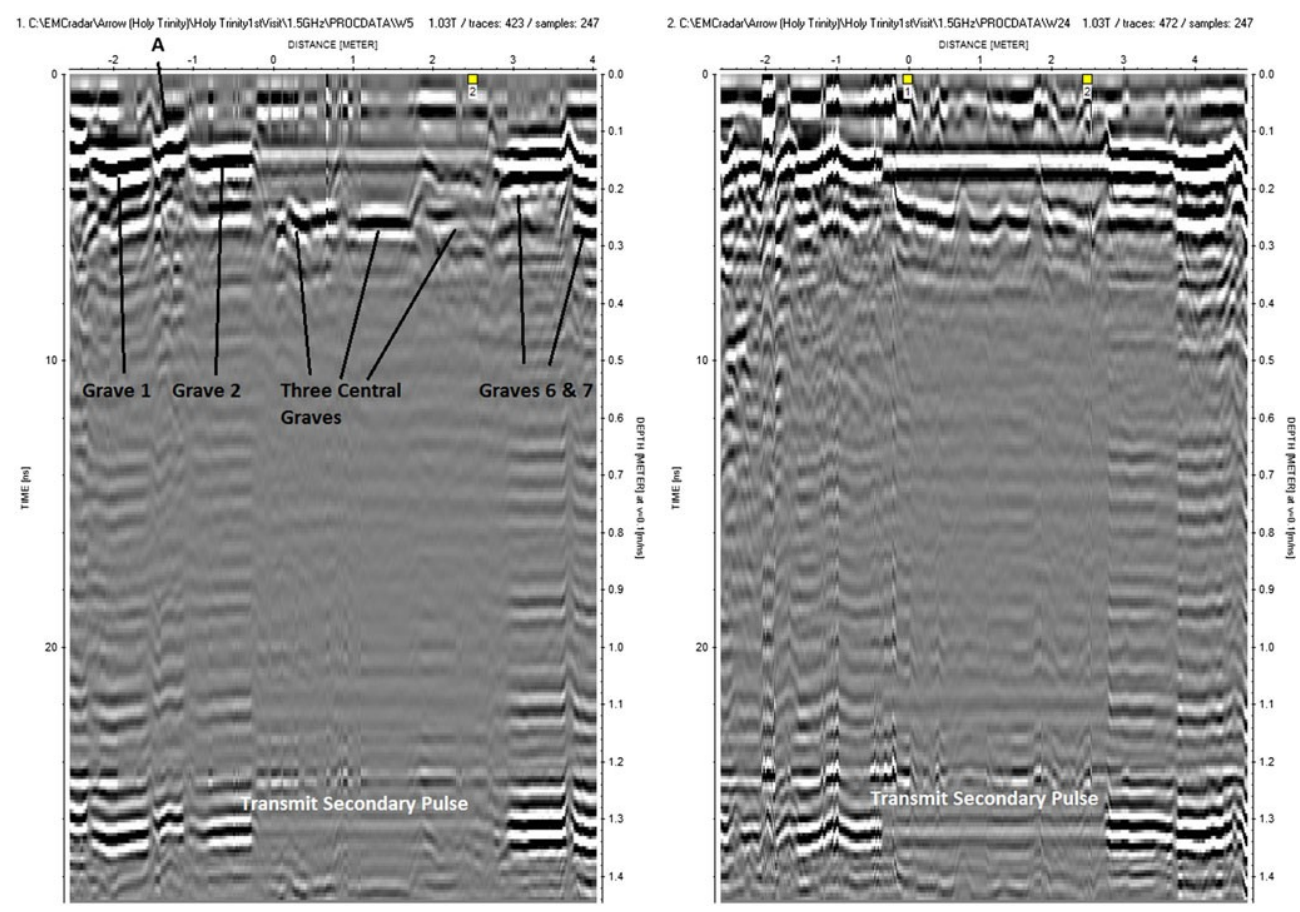

FIGURE 8 1.5GHz Survey lines W5 and W24 showing the line of graves below the ledger stones in the upper chancel floor, the dividing line between the two northern tombs and the differing depths of the graves [Colour figure can be viewed at wileyonlinelibrary.com]

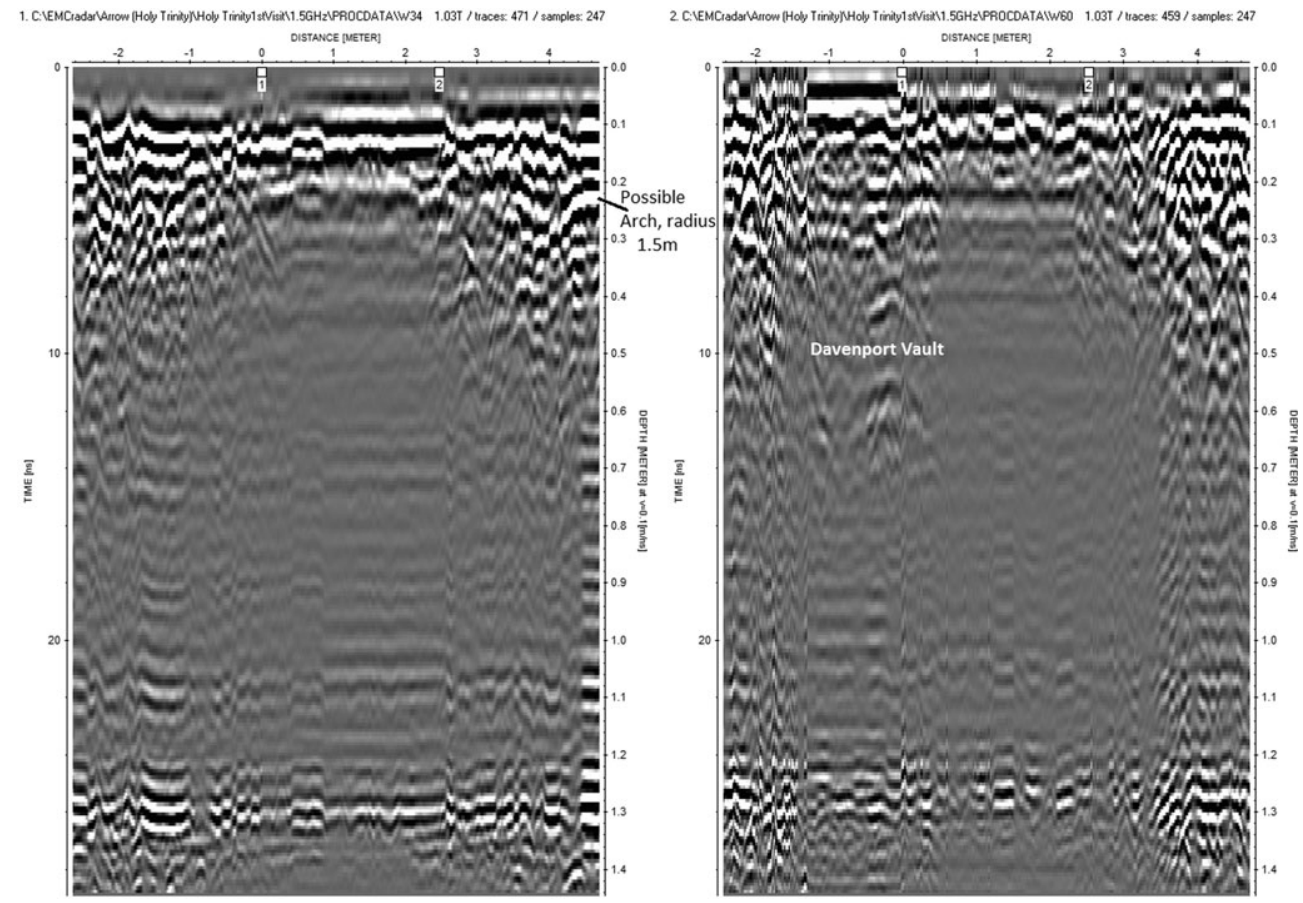

FIGURE 9 1.5GHzSurvey lines W34 and W60 showing the greater subsurface complexity below the lower chancel floor and the evidence for vaults to the South and North 


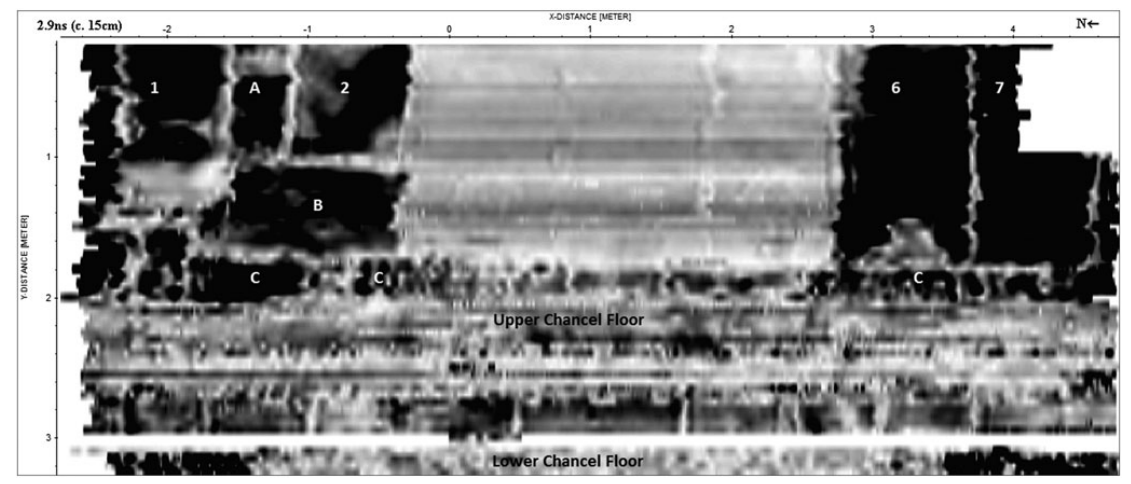

FIGURE 10 1.5GHz Time Slice beneath the upper chancel floor and part of the lower chancel floor at $2.9 \mathrm{~ns}(\mathrm{c} 15 \mathrm{~cm})$

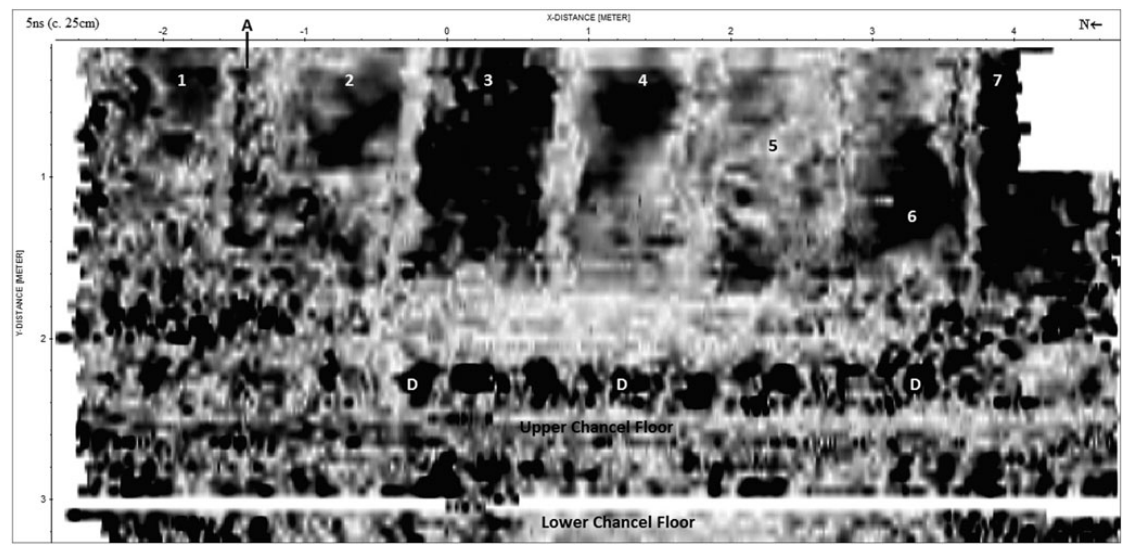

FIGURE 11 1.5GHz Time Slice beneath the upper chancel floor and part of the lower chancel floor at $5 \mathrm{~ns}(\mathrm{c} .25 \mathrm{~cm})$
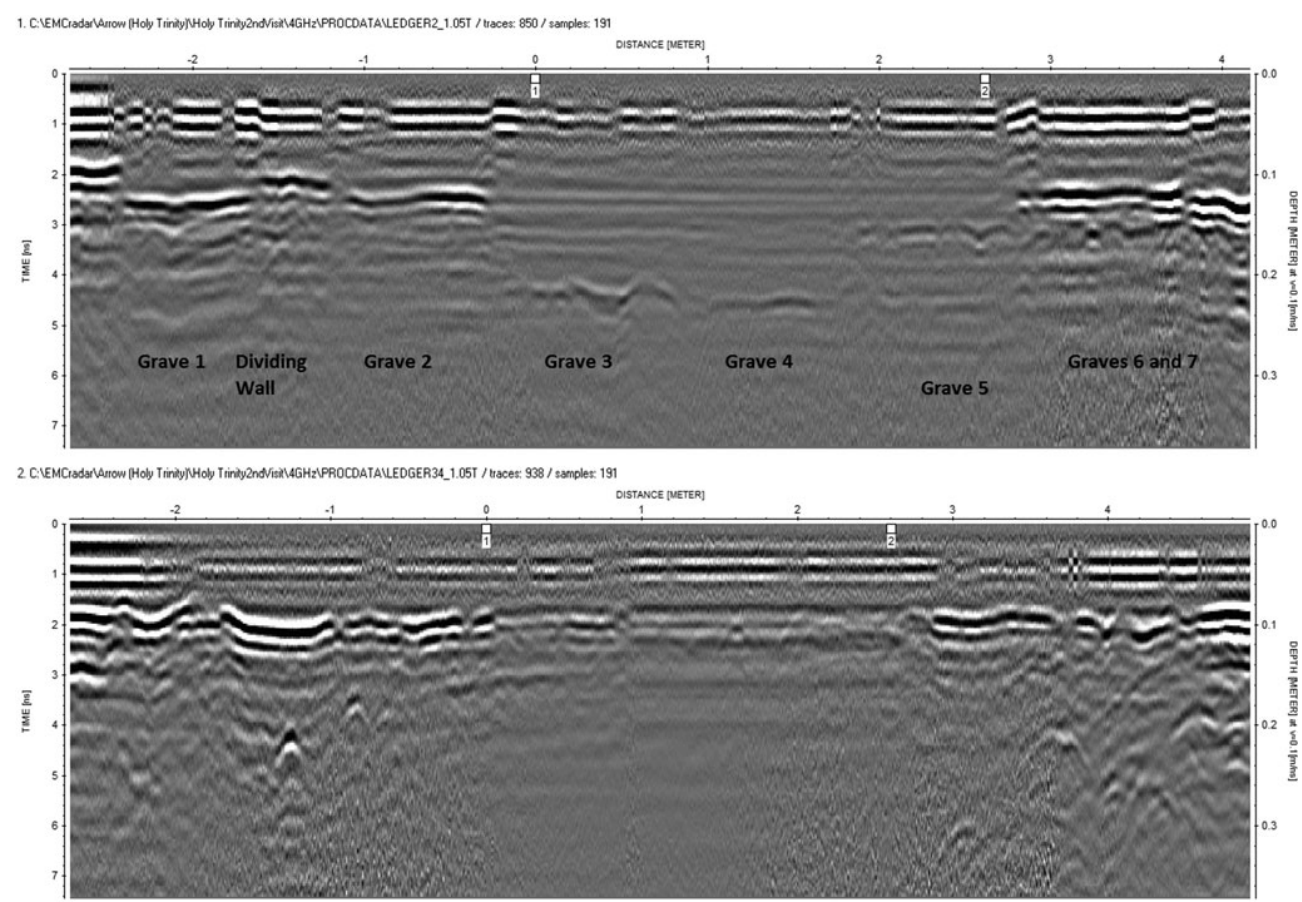

FIGURE 12 4GHz Survey lines 2 and 34 showing the evidence for the graves beneath the ledger stones (top) and subsurface features further to the West but still within the upper chancel floor (below) 


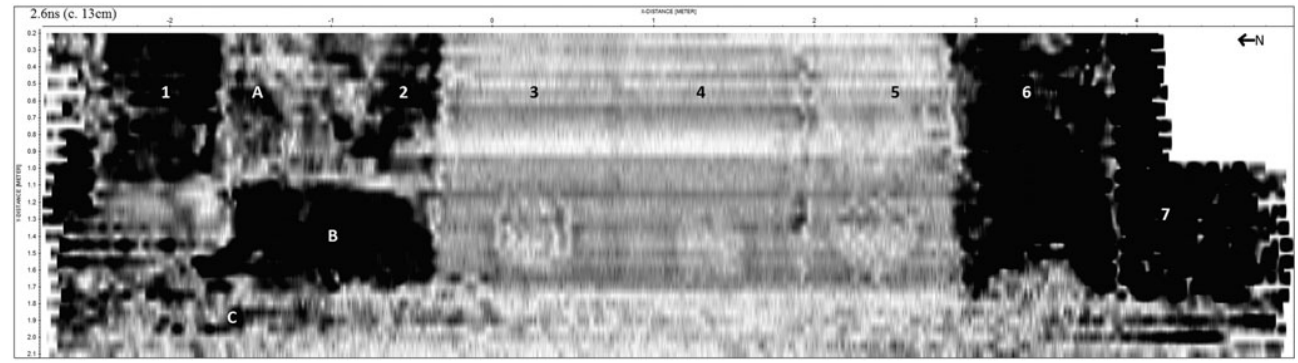

FIGURE 13 4GHz Time slice from beneath the upper chancel floor, extracted at $2.6 \mathrm{~ns}(\mathrm{c} .13 \mathrm{~cm})$ showing the position of the graves, North/South feature ' $A$ ' and East/West feature ' $B$ '

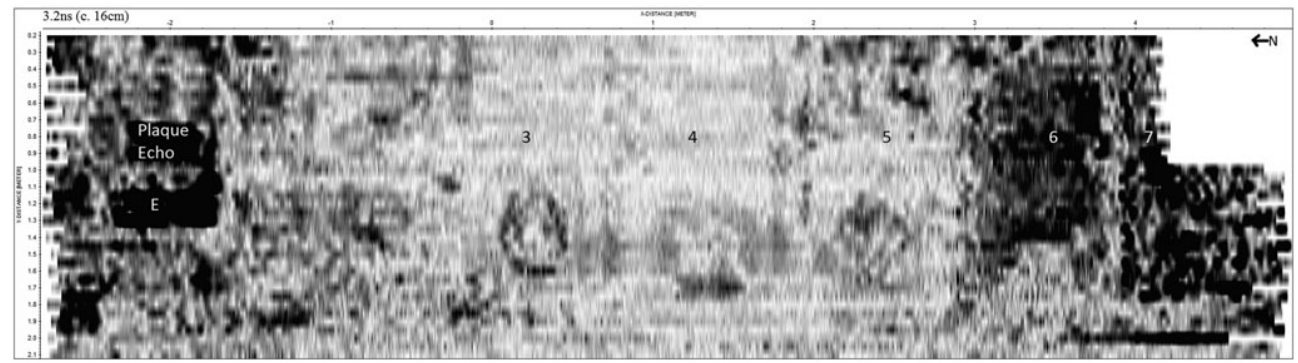

FIGURE 14 4GHz Time slice from beneath the upper chancel floor, extracted at $3.2 \mathrm{~ns}(\mathrm{c} .16 \mathrm{~cm})$ showing the outline of a small rectangular feature ' $E$ ' in Ann Hathaway's grave as well as ringing from the metal plaque at floor level

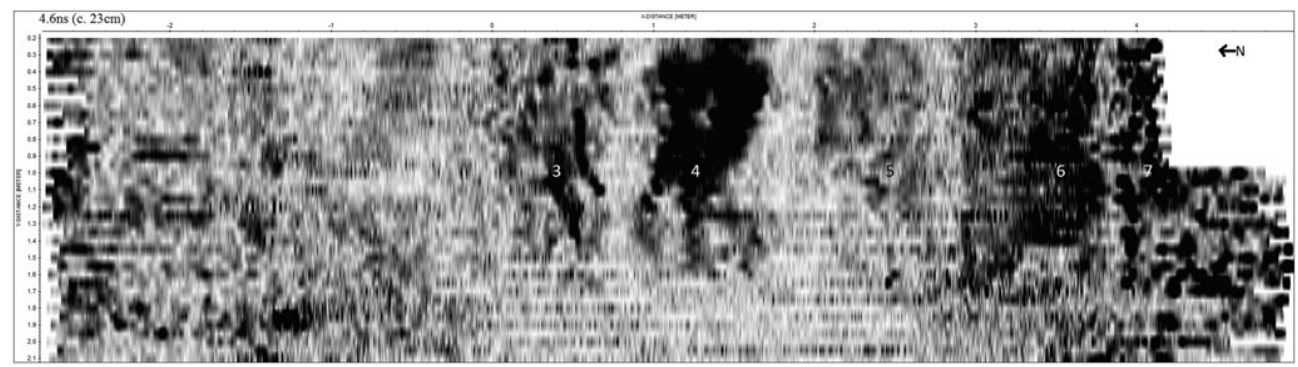

FIGURE 15 4GHz Time slice from beneath the upper chancel floor, extracted at 4.6ns $(\mathrm{c} .23 \mathrm{~cm})$ showing the irregularly shaped areas of strong signal return within the three centrally placed graves 

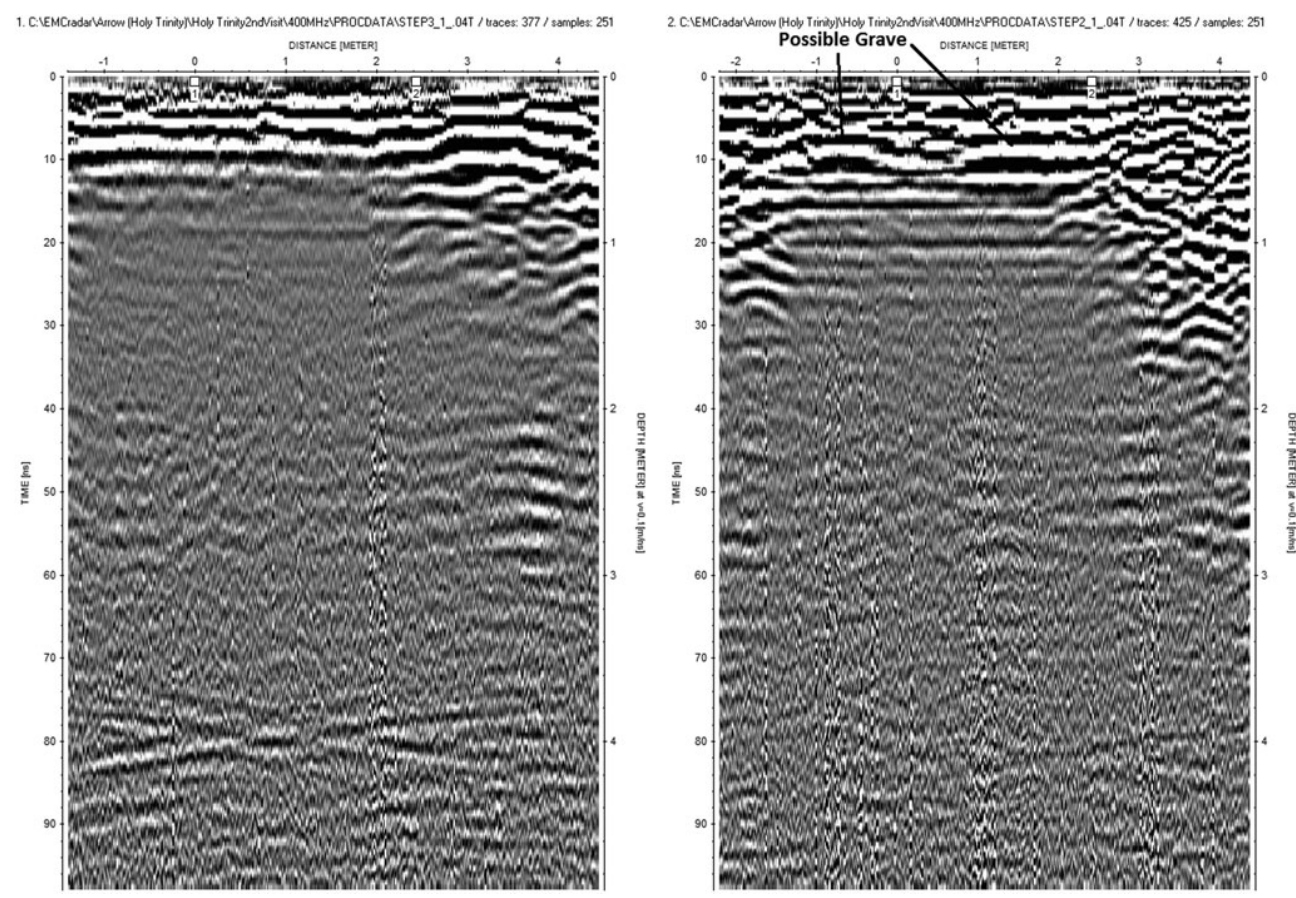

FIGURE $16400 \mathrm{MHz}$ Survey lines 2 and 3 from the lower altar step showing the evidence for possible shallow graves

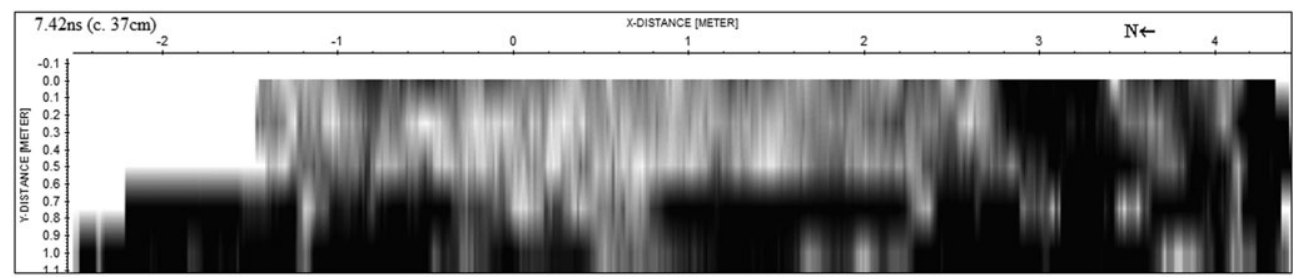

FIGURE 17 400MHz Time Slice from the lower altar step, extracted at $7.42 \mathrm{~ns}$ (c. $37 \mathrm{~cm})$ showing a slightly diffuse pattern below the lower altar step which might equate to the eastern end of the series of burials below the upper chancel floor, the depth being equivalent to that of Figure 5

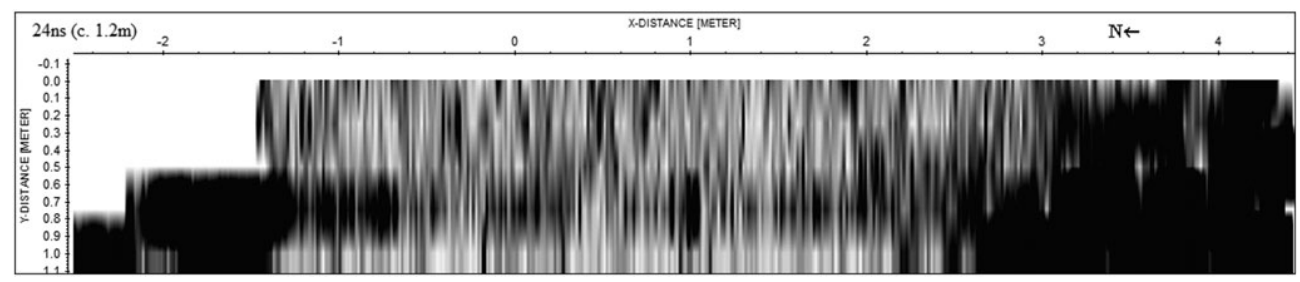

FIGURE 18 400MHz Time Slice extracted at 24ns (c. 1.2m) showing possible substantial graves in the NW and SW corners of the lower altar step 

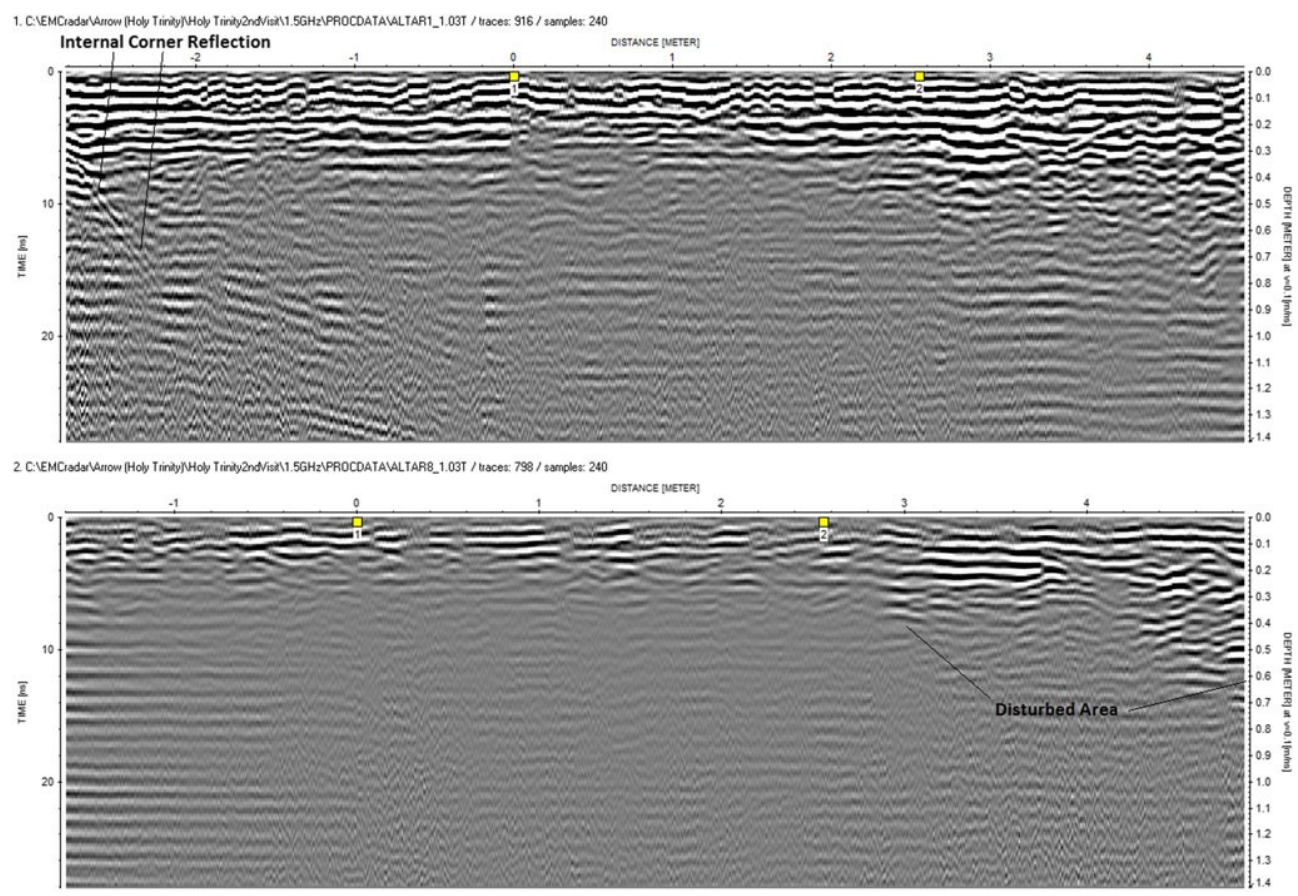

FIGURE 19 Survey Lines 1 and 8 from the 1.5GHz survey of the lower altar step showing evidence of graves and of levelling of the ground [Colour figure can be viewed atwileyonlinelibrary.com]

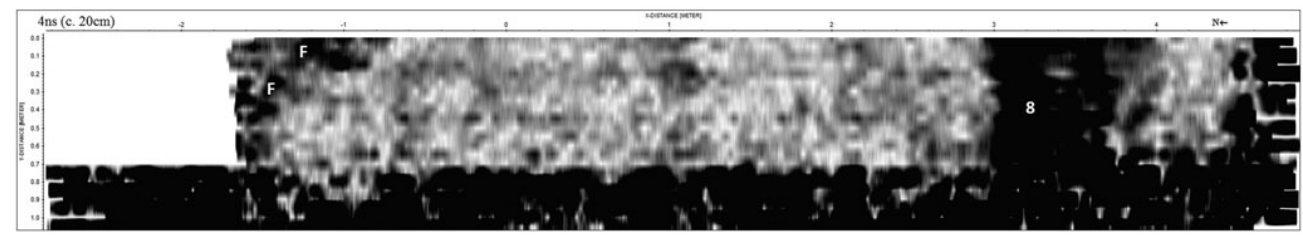

FIGURE $201.5 \mathrm{GHz}$ Time Slice extracted at 4ns (c. $20 \mathrm{~cm})$ showing evidence of grave 8 beneath the lower altar step

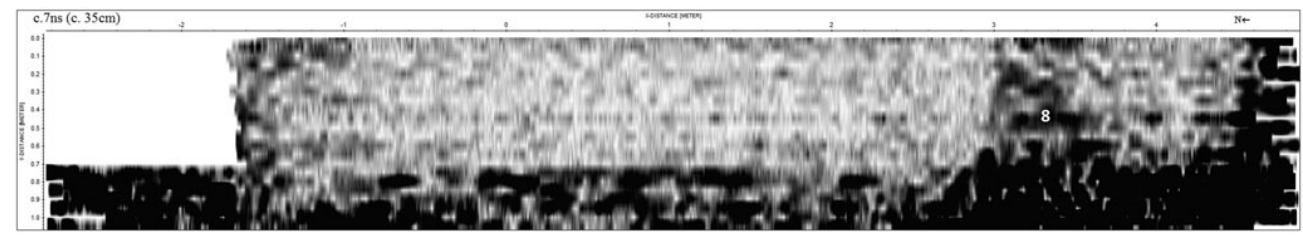

FIGURE $21 \quad 1.5 \mathrm{GHz}$ Time Slice extracted at $7 \mathrm{~ns}(\mathrm{c} .35 \mathrm{~cm})$ from beneath the lower altar step showing lack of continuity with the graves below the area of the ledger stones in the upper chancel floor 